\title{
Report
}

\section{Analysis of Mt Kenya Glaciers Recession Using GIS and Remote Sensing}

\author{
Purity Njeri Mwaniki*, David Kuria, Charles Ndegwa Mundia, Godfrey Makokha \\ Institute of Geomatics, GIS and Remote Sensing in Dedan Kimathi University of Technology, Nairobi, Kenya
}

Email address:

mwanikipurity4@gmail.com(P. N. Mwaniki)

${ }^{*}$ Corresponding author

\section{To cite this article:}

Purity Njeri Mwaniki, David Kuria, Charles Ndegwa Mundia, Godfrey Makokha. Analysis of Mt Kenya Glaciers Recession Using GIS and Remote Sensing. American Journal of Environmental Science and Engineering. Vol. 2, No. 1, 2018, pp. 1-16.

doi: 10.11648/j.ajese.20180201.11

Received: March 26, 2018; Accepted: April 16, 2018; Published: May 17, 2018

\begin{abstract}
This research analyses the changes in coverage Mt Kenya glaciers in a bid find what has been causing the retreat of these glaciers. Optical Landsat data for 1984 to 2017 and Climatic data of the same years were used. Glaciers and forest coverage were extracted from Landsat images and its thermal band was used to extract temperature data. Correlation with the respective year's climatic data and forest cover area were done to justify the assumption that the shrinkage in the glaciers coverage has been caused by changes in climate and/or deforestation. Then using the historical EC Earth model climate data predictions for 1984-2017 and historical observed data for the same years, bias correction factors were computed and used to correct the future model data for the years (2018-2045). Since the data was extracted for only four points around Mt Kenya, Interpolation was then done to obtain the Precipitation and Temperature for the mountain peak (since the glaciers are found at the peak) using the IDW technique. Prediction of glacier area coverage was then done using these interpolated climate data. In order to predict the future glacier cover, linear equations of the form $y=a_{1} x_{1}+a_{2} x_{2}+b_{o}$ of the interpolated climate data (for 2018-2045) and computed glacier areas for (1984-2017) were formed. The $\mathrm{a}_{1} \mathrm{a}_{2}$ and $\mathrm{b}_{0}$ in the equation are constants obtained from SPSS (a statistical software). X1 and $\mathrm{x} 2$ are the predicted Temperature and Precipitation respectively. Predictions were done for RCP scenarios 8.5 and 4.5. The results of prediction showed that the current trend of glacier thinning is going to continue but at a slower rate compared to the rapid melting that was observed for the period 1984-2017. However, Mt Kenya glaciers are likely to have completely disappeared by the year 2100 .
\end{abstract}

Keywords: Glaciers and Forest Coverage, Climate, Prediction

\section{Introduction}

The term glacier refers to a perennial natural body of surface ice which visibly moves under its own weight in response to gravitational force. Glaciers move from upper reaches with a net gain of ice mass to lower regions where mass loss dominates [1]. Although glaciers are generally thought of as polar entities, they also are found in mountainous areas throughout the world, on all continents except Australia and even at or near the Equator on high mountains in Africa and South America [2].

In East Africa, glaciers began to recede in the 1880's [3]. Well-documented examples of glacial recession in East Africa include the Mount Kenya, Ruwenzori and Kilimanjaro glaciers. The widespread retreat is all the more notable because these tropical mountain glaciers are old. They have survived thousands of years of natural climate fluctuations, only to dwindle at a time when other climate indicators are showing the results of human influence on climate. The problem thus, is to determine which of the many characteristics of climate change they are indicating and to what extent these changes can be attributed to the train of events set in motion by increased of human production of greenhouse gases [4].

Variations in many conditions can influence glacial melt this includes precipitation, humidity, temperature, cloud cover, increased solar radiation and direct evaporation from the glacier surface and the mountain's relief [5]. 
In East Africa, the dramatic shrinking of Kilimanjaro's glaciers has attracted global attention [6]. The ice on Mount Kilimanjaro has been retreating both in thickness and in area, with the latter's decline being the most dramatic [7]. Compared to 1800 when the ice covered about $20 \mathrm{~km}^{2}$, by 2003, the area had shrunk to about $2.51 \mathrm{~km}^{2}$ [8]. An estimated 82 per cent of the ice cap that crowned the mountain when it was first thoroughly surveyed in 1912 is now gone, and the remaining ice is thinning by as much as a meter per year in one area. According to some projections, if recession continues at the present rate, the majority of the remaining glaciers on Kilimanjaro could vanish by 2020 [9]. Other studies have showed that deforestation around Mt Kilimanjaro has affected the climate around it and as result, it is being considered as one of the contributing factors to the thinning of glaciers being experienced there [10-11].

On the other hand, Mt. Ruwenzori glaciers occur on only three of the range's peaks: Stanley, Speke and Baker. The glacial recession on the Ruwenzori Mountain has been attributed to higher air temperatures and less snow accumulation during the 20th century [12]. It is also possible that decreasing cloud cover over the same time has contributed to vaporization of these glaciers [12]. On one visit in 1974, it was estimated that since 1958, the Speke Glacier had retreated by 30 to $40 \mathrm{~m}$ and shrunk laterally by 10 to $20 \mathrm{~m}$ [5].

In Kenya, studies of the Lewis Glacier (which is the largest glacier) on Mount Kenya found that higher temperatures during the 1900 s were a greater cause of its shrinking than sun exposure [7]. Other studies have shown that some warming during the 20th century and associated rises in atmospheric humidity, along with a possible contribution of continued solar radiation forcing are the causes of Mount Kenya's recent ice losses [13].

Mount Kenya lost $92 \%$ of its ice cap in the last century. Of the 18 ice entities that covered the mountain peaks, at the end of the 19th century, 9 had disappeared altogether and all suffered substantial loss [14]. The Gregory glacier, which joined with the Lewis on one end, was the latest victim having disappeared by March 2011 and only debris covered ice remnants of unknown thickness are left [15].

In Kenya, the forest cover dramatically decreased such that in 1986 a presidential declaration led to banning of exploitation of indigenous forest. From time-to-time, licensees would put up a case claiming to be allowed to remove materials pre-felled and paid for, that they had not been able to collect by the time the ban was announced. Individual cases were authorized on occasion but complications emerged as authorization was abused and fresh logging took off again. Even though the ban was issued back in 1986, individuals have continued to apply for permits that have been approved as recently as this year. Large scale logging of indigenous forests exists today more than ever before despite the ban [16].

The magnitude of forest destruction is very high. This may have significantly affected the climate of the areas around the mountain and consequently it may have led to glacier recession.

\section{Data and Methodology}

\subsection{Study Area}

The Mount Kenya is the second highest mountain in Africa after Mt Kilimanjaro, it is an isolated, extinct, denuded volcano (before glaciation it was $7000 \mathrm{~m}$ high) was built up by intermittent volcanic eruptions between 3.1 and 2.6 million years ago [17]. It was covered by an icecap for thousands of years and this resulted in very eroded slopes [18]. The highest peaks of the mountain are Batian $(5199 \mathrm{~m})$, Nelion (5188m) and point Lenana $(4985 \mathrm{~m})$.

It lies on the equator $\left(0^{\circ} 6^{\prime} \mathrm{S}, 37^{\circ} 18^{\prime} \mathrm{E}\right)$, approx. $150 \mathrm{~km}$ NNE of Nairobi. The mountain is located in the Mount Kenya National Park, which is a designated protected area. The national park covers an area of 700 square kilometres and was established in 1949 [19].

The climate of Mt. Kenya region is largely determined by altitude. Average temperatures decreases by $0.6^{\circ} \mathrm{C}$ for each $100 \mathrm{~m}$ increase in altitude. An afro-alpine type of climate, typical of the tropical East African high mountains, characterizes the higher ranges of Mt. Kenya. The altitudes with the highest rainfall are between 2,700 and 3,100m, while above $4,500 \mathrm{~m}$ most precipitation falls as snow or hail. Frosts are common above 2500 above mean sea level [20].

Rainfall pattern in Mt Kenya ecosystem is bimodal. It ranges from $900 \mathrm{~mm}$ in the north Leeward side to $2,300 \mathrm{~mm}$ on the southeastern slopes (Windward side) of the mountain (Survey of Kenya, 1966) with maximum rains falling during months of March to June and October to November. The driest months are January and February with the windward side experiencing the strongest effects of the trade wind system [20].

The mountain is one of the five main water towers of Kenya, the others being the Aberdare ranges, Mau complex, Mt. Kenya and Cherangani hills. Mt. Kenya is the source of two of Kenya's largest rivers, the Tana and Ewaso Nyiro [20].

Vegetation types and species distribution are distinguished according to the different climatic zones and altitudes, most obviously through variation in vegetation structure, cover and composition.

The following vegetation zones are apparent from the high altitudes to lower altitudes.

(i) Moorland

This lies between $3000 \mathrm{~m}$ and $3500 \mathrm{~m}$. It's also referred to as Ericaceous belt and is mainly covered with giant heath, African sage (Artemisia afra) and several Gentians (Swertia spp). It is also characterized by smaller trees in glades, such as the East African Rosewood (Hagenia abyssinica) and St. John's Wort (Hypericum spp). Trees are covered with moss and lichens (Usnea spp).

\section{(ii) Pure Bamboo}

This is a pure bamboo (Arudinaria spp) zone occurring between 2550 and 2650 above mean sea level. The main purpose was supplying commercial forest products to the forest industries located within the forest adjacent areas. Main commercial tree species planted include Cypress, Pines, and Eucalypts. 


\section{(iii) Nyayo Tea Zone}

This area was opened up by the Nyayo Tea Zones Development Corporation in 1986 with the aim of promoting forest conservation by providing a buffer zone to check against human encroachment into forest reserves [20].

Mt. Kenya Forest Reserve is also home to a wide diversity of fauna. These include African elephant, leopard, giant forest hog, Bongo and the black fronted duiker. There are also over ten species of ungulates in Mt. Kenya forest reserve. These include the duiker, bushbuck, deffassa waterbuck, mountain reedbuck, bush pig, the common zebra, eland, steenbok, Harveys red duiker and common duiker. These animals are spread over the entire ecosystem but their densities are low in the southern slopes. Cape buffaloes occur on the western slopes of the mountain but are rare on the eastern slopes possibly because of their preference for open bushland.

Several primates are found in Mt. Kenya forest reserve, the most common being the black and white colobus and Sykes monkey. These primates are widely spread within the forest reserve [20].

Communities living adjacent to Mount Kenya Forest are mainly agriculturists. The Kikuyu community occupy the western side of Mount Kenya, Meru people on the eastern side, while to the south is the Embu ethnic group. Other tribes that interact with the ecosystem include the pastoralist communities who occupy the northern part of the mountain. The total population of the community that live within the districts that border the ecosystem was 17.6 million in 1999
(1999 Kenya population census data).

Land ownership within the area falls under different categories of land tenure. The agricultural lands - both large-scale (horticulture and floriculture) and small scale are held under freehold (Private ownership), whereas ranches and sanctuaries are held under leasehold as government lands. Other types of land tenures include public lands and trust land [20].

Agriculture is the main economic activity in the areas adjacent to the forest reserve. The type of agriculture practiced and productivity potential depend mainly on altitude, which in turn determines the temperatures and amount of rainfall. On the eastern and southern side of the mountain, where rainfall is high, intensive arable farming is practiced. In the upper areas, potatoes, pyrethrum and tea are grown. In the mid-latitudes zones, coffee, maize, beans, rice and bananas and mixed livestock farming are practiced, while in the lower zones, tobacco, cotton, sorghum, millet, pigeon peas and cow peas are most dominant crops [20].

Mt Kenya ecosystem has attractive sceneries and great potential for tourism development, which is yet to be fully harnessed. The ecosystem is endowed with unique geomorphologic features, cultural and historical sites that are of great tourism attraction. In addition, there is a diversity of wildlife populations which attract visitors. The ecosystem supports tourism in the region by offering a diversity of activities such as bird watching, trout fishing, walking and wilderness trails [20]. Figure 1 shows the area of study.

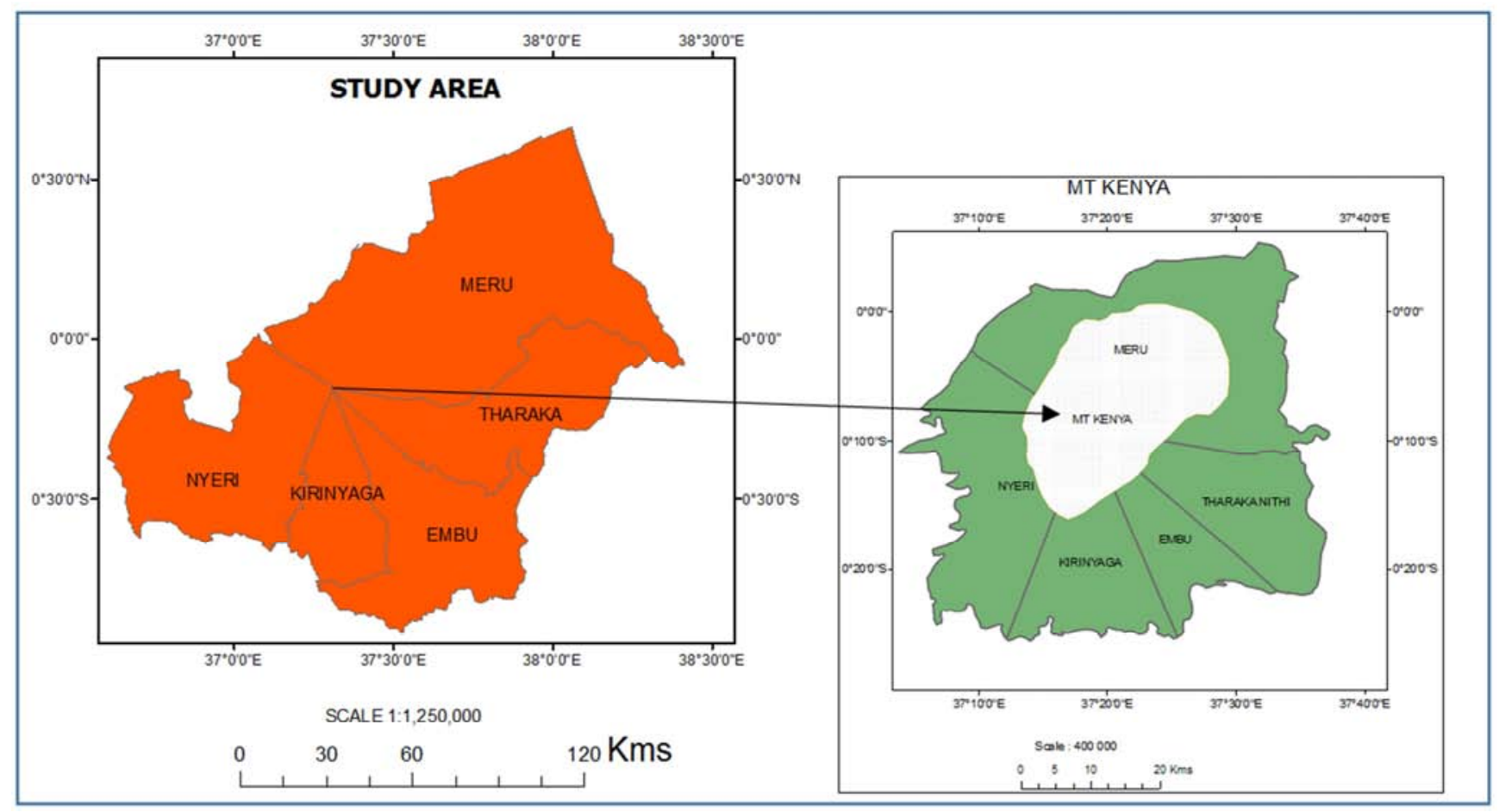

Figure 1. Study Area.

\subsection{Data}

Most of the Landsat images used for this study (as shown in table 1), can be downloaded from Earth Explorer and
GLOVIS websites. Historical climate data was also available online in the NASA POWER website in terms of daily observations from the year 1983. NASA POWER is a renewable energy resource website of global meteorological 
and surface solar energy climatology data form NASA satellites, at a resolution of $1^{0}$ by $1^{0}$. Precipitation data was downloaded as raster from the Climate Hazards Infrared Precipitation with Station data (CHIRPS) website, then extracted to values using the coordinates of the point of interest. CHIRPS is a Quasi - global rainfall dataset spanning $50^{\circ} \mathrm{S}-50^{\circ} \mathrm{N}$ and dating back to 1981 . It incorporates $0.05^{\circ}$ resolution satellite imagery with in-situ station data to create gridded rainfall time series for trend analysis and seasonal drought monitoring. The modelled climatic data (temperature and rainfall) were extracted from the EC Earth model for Representative Concentration Pathways (RCPs) 4.5 and 8.5.

Table 1. Types of Data and Sources.

\begin{tabular}{llllll}
\hline Type of image & sensor & date of acquisition & Path/row & spatial resolution \\
\hline Landsat 5 & TM & $17 / 12 / 1984$ & $160 / 60$ & $30 \mathrm{M}$ & source \\
Landsat 5 & TM & $25 / 05 / 1987$ & $168 / 60$ & $30 \mathrm{M}$ & RCMRD \\
Landsat 5 & TM & $12 / 03 / 1992$ & $168 / 60$ & $30 \mathrm{M}$ & RCMRD \\
Landsat 5 & TM & $22 / 05 / 1995$ & $168 / 60$ & $30 \mathrm{M}$ & Earth Explorer \\
Landsat 7 & ETM & $21 / 02 / 2000$ & $168 / 60$ & $30 \mathrm{M}$ & RCMRD \\
Landsat 7 & ETM+ & $06 / 05 / 2005$ & $168 / 60$ & $30 \mathrm{M}$ & RCMRD \\
Landsat 5 & TM & $20 / 11 / 2009$ & $168 / 60$ & $30 \mathrm{M}$ & GLOVIS \\
Landsat 7 & ETM & $25 / 03 / 2012$ & $168 / 60$ & $30 \mathrm{M}$ & GLOVIS \\
Landsat 7 & $\mathrm{ETM}^{+}$ & $02 / 03 / 2015$ & $168 / 60$ & $30 \mathrm{~m}$ & Earth Explorer \\
Landsat 7 & $\mathrm{ETM}^{+}$ & $26 / 05 / 2017$ & $168 / 60$ & $30 \mathrm{~m}$ & Earth Explorer \\
\hline
\end{tabular}

\subsection{Methodology}

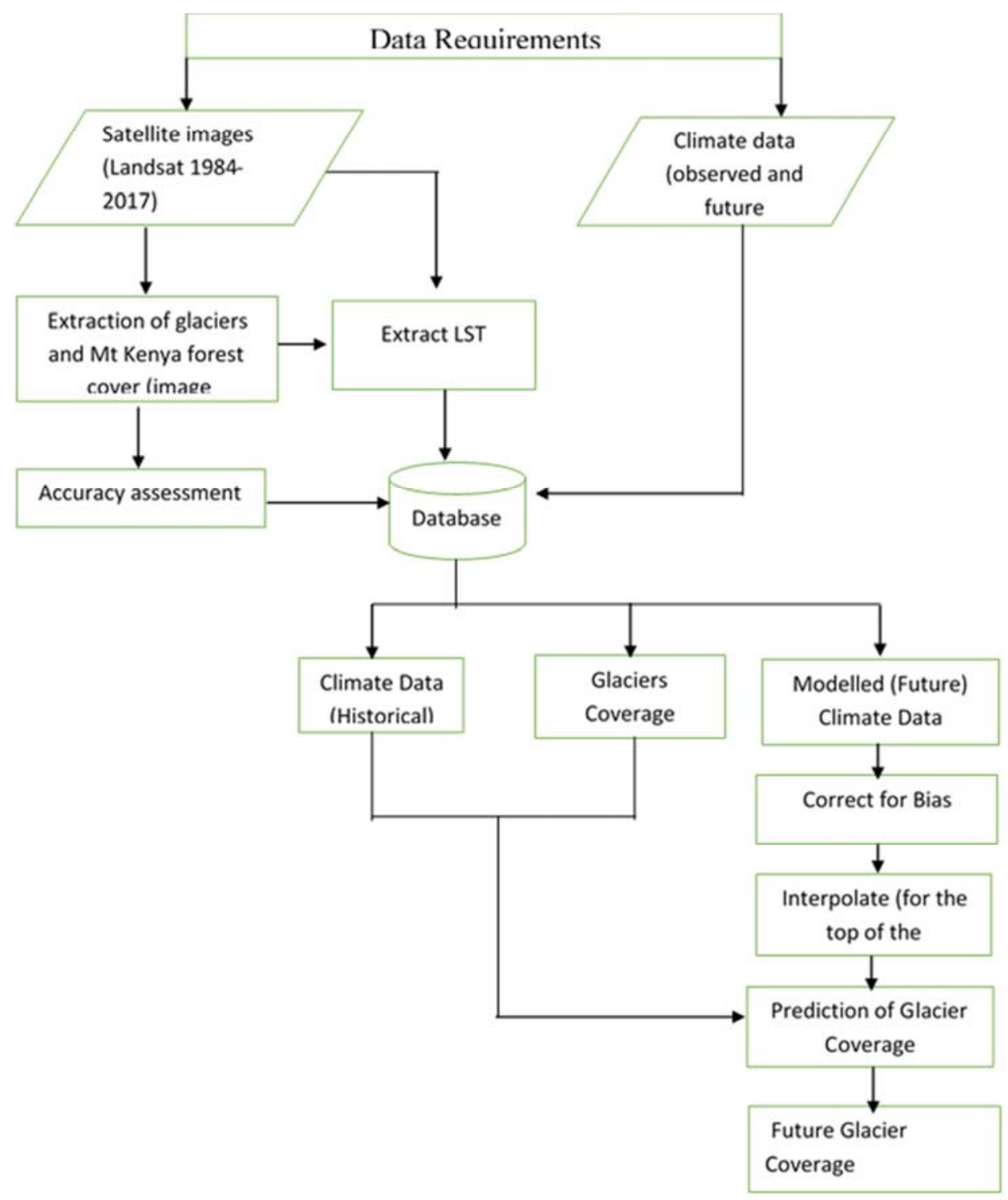

Figure 2. The work flow diagram. 
The Landsat7 image for the years 2005, 2012,2015 and 2017 had missing scan lines and had to be destripped using the Landsat gap fill plugin and the gap mask which was provided with the images.

The area of interest (AOI) was then subset but because of cloud cover, it was not possible to use a shapefile of the whole of Mt Kenya to subset all the images uniformly. On some of the images, clouds occurred too close to the mountain peak, which was the area with the most snow cover. Therefore, an irregular AOI was generated manually and used to subset all the other images.

Computation of band ratio is the best method of differentiating between glaciers and non-glacier areas in an image [4].

$$
\text { band ratio }=\frac{\text { band } 4}{\text { band } 5}
$$

The raster images that resulted from band rationing were single layer from which it was not possible to compute the areas of the various layers of interest therefore, since one of the objectives of this research was to compute area differences, supervised classification was the best option. Band rationing separates the melted glacier areas and the solid glacier areas therefore; it was used as a guide when selecting the training areas for the glaciers as can be shown by figures 7,8 and 9 but could not be used as the source of the training data since it is a black and white.

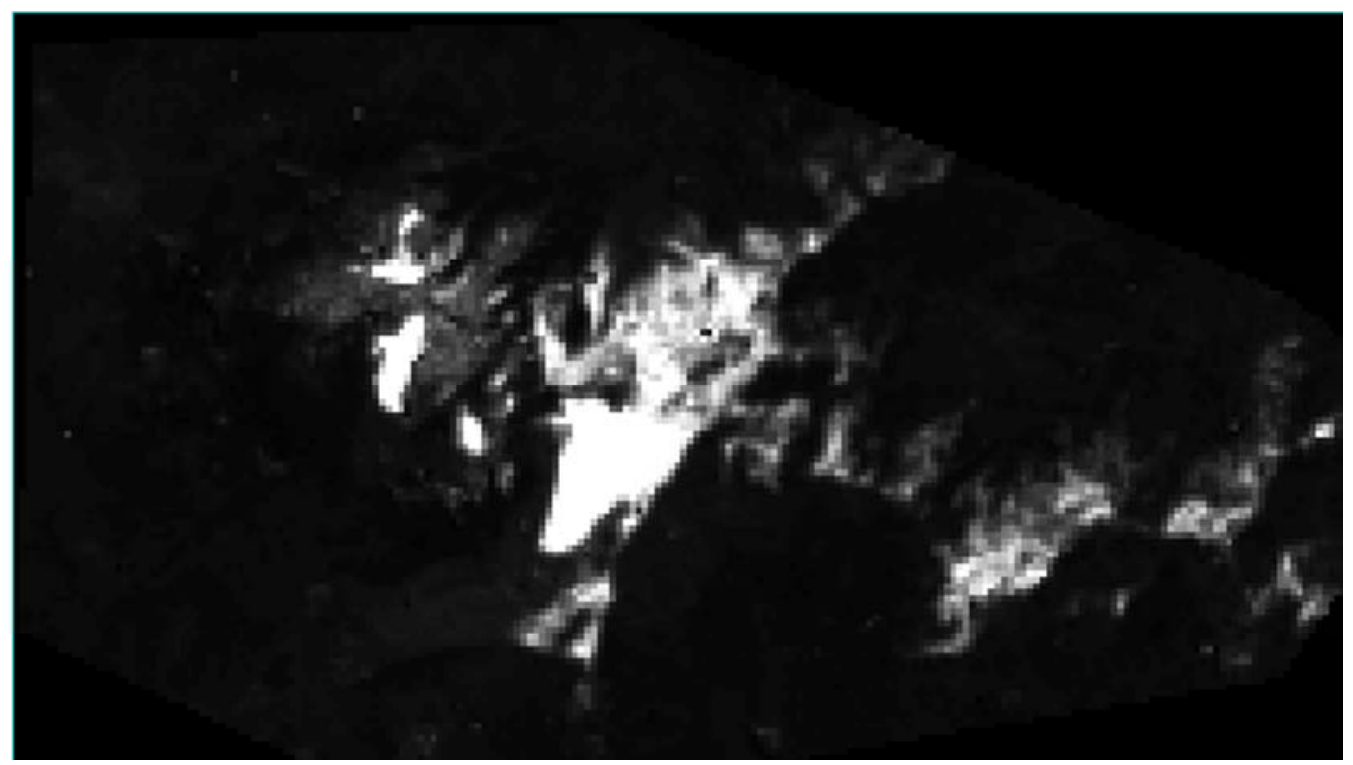

Figure 3. 1984 Band Ratio image.

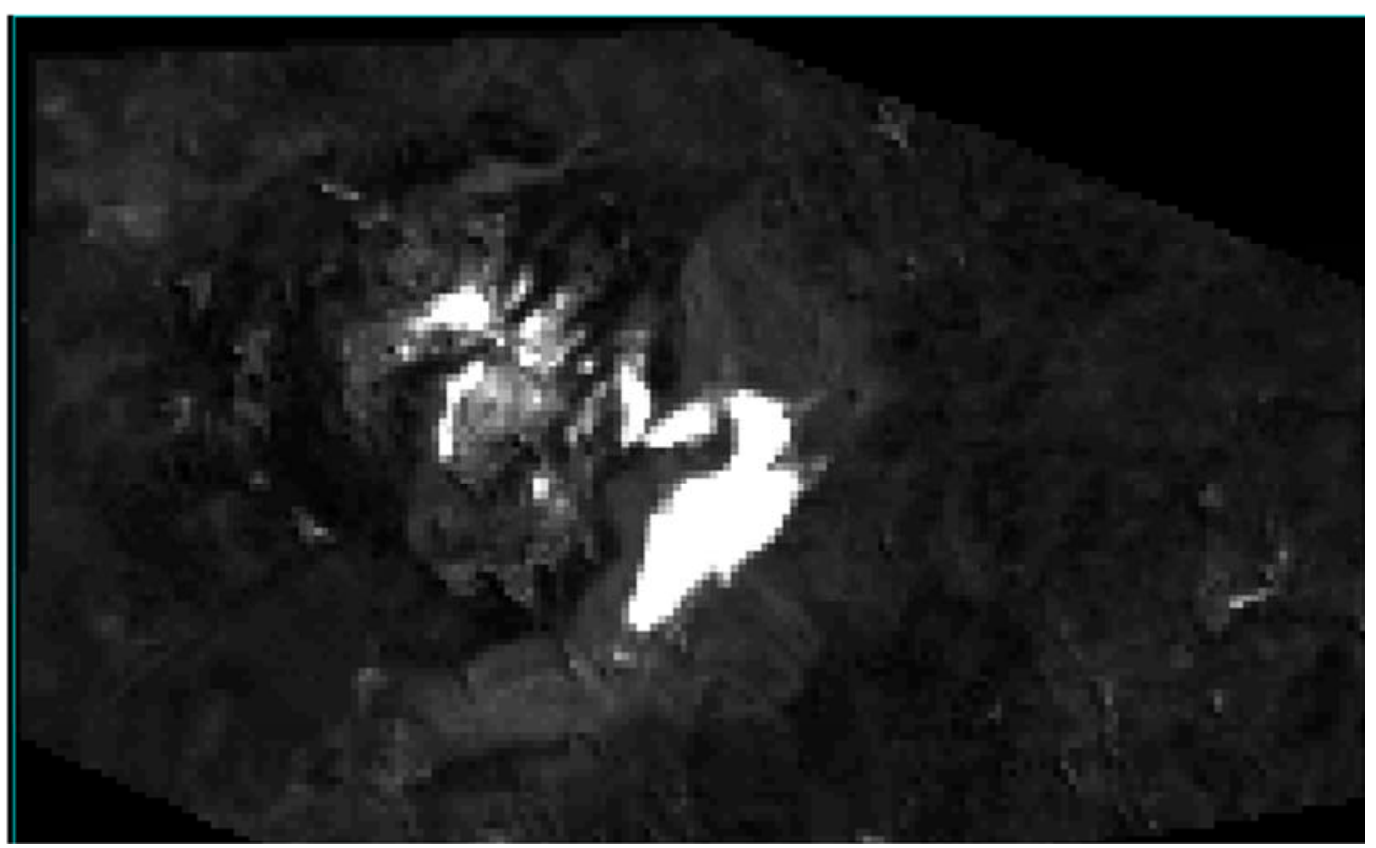

Figure 4. 1987 Band Ratio image. 


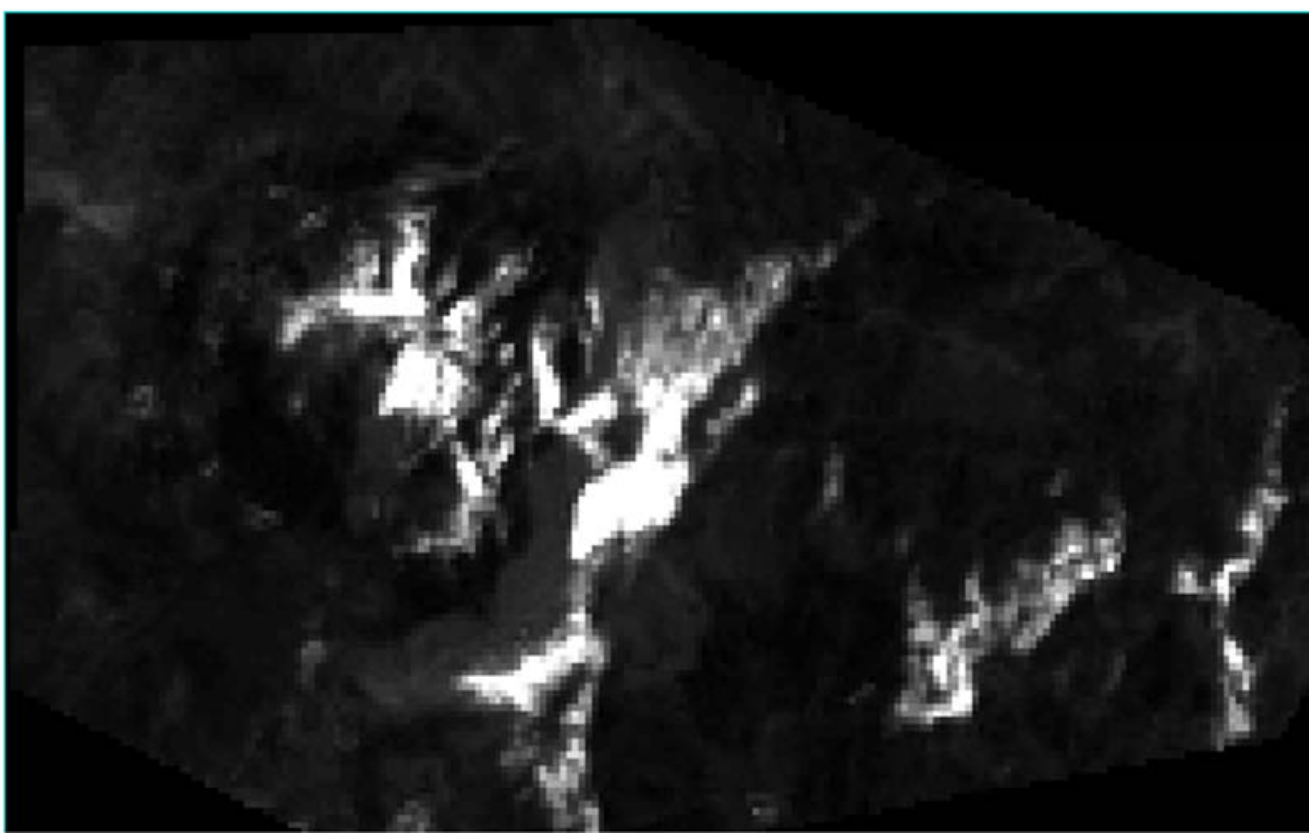

Figure 5. 2009 Band Ratio image.

The automatic weather station on top of the mountain was installed in September 2009, its data records could not be sufficient for this study. Also considering that the data records for several months were missing due to malfunction of the automatic weather station [21]. The temperature data that was used for this study was therefore extracted from Landsat 5 and 7, thermal band 6. Analysis of Observed Climate Trends was then done using line graphs to show for example how temperature has changed over the years. On the graph, the various years were plotted on the X-axis (as the independent variable) and the climate variables as the dependent variables, on the Y-axis. Comparative analyses (of the historical observed data 1984-2017) were done using line graphs for the climate variables (temperature, wind speed, solar insolation, precipitation and relative humidity) and glaciers and forest area coverage. For further analyses, correlation coefficients were used.

Before the IPCC climate estimates could be used to predict glacier area coverage they had to be corrected for bias. This was done by correlating the 1984-2005 observed climate data with the EC-earth model data output for the same period to get the bias relation between the two observations. Thus, the values got were used to do bias correction to the future (2018-2045) estimates. The study was limited to the two variables (temperature and rainfall) as they were the only data available. The methods used for bias correction included;

The simple shift method

$$
T_{S H}(t)=T_{R A W}(t)+\left(0_{\overline{R E F}}-\mathrm{T}_{\overline{R E F}}\right)
$$

Where; $\mathrm{T}_{\mathrm{SH}} \quad(\mathrm{t})$ is the bias corrected precipitation/temperature, $\mathrm{T}_{\mathrm{RAW}}(\mathrm{t})$ raw model output, $\mathrm{T}_{\overline{R E F}}$ mean of model output and $\mathrm{O}_{\overline{R E F}}$ mean of observed data. This method is also referred as the Additive correction of temperature [22].

Multiplicative method

$$
p_{B C S}^{i}(t)=p_{\text {mod }}^{i}(t) * \frac{p \frac{i}{o b s}}{p_{\text {mod }}^{i}}
$$

Where $\mathrm{P}_{\mathrm{BCS}}^{\mathrm{i}}$ is the bias corrected precipitation/temperature time-series, $\mathrm{P}_{\text {mod }}^{\mathrm{i}}$ is the original model precipitation/temperature time-series, and $P \frac{i}{o b s}$ and $P \frac{i}{m o d}$ are the mean values of the observed data and model respectively. $i$ is an index of the month [22].

The delta method

$$
T_{B C}(t)=0_{\overline{R E F}}+\frac{\sigma O_{R E F}}{\sigma T, R E F}\left(T_{\overline{R A W}(T)-} \mathrm{T}_{\overline{R E F}}\right)
$$

$\mathrm{O}_{\overline{R E F}}$ and $\mathrm{T}_{\overline{R E F}}$ are mean of observed data and mean of model respectively and $\sigma T_{\text {, } \mathrm{REF}}$ and $\sigma O$, REF represent standard deviation of model and observation respectively. $T_{\mathrm{RAW}}$ is the raw model output [22].

The model data that was provided was extracted only for four stations whose coordinates were as shown in table 2 below. The temperature and precipitation of the mountain peak then had to be interpolate using the Inverse Distance Weighting (IDW) technique. This technique was preferred because previous studies have found this to be the best compared to Kriging, Spline and others.

Table 2. Coordinates of Interpolation Points.

\begin{tabular}{lll}
\hline Station & Coordinates N (m) & E (m) \\
\hline Meru & 11056.1 & 349765 \\
Embu & 9944714.6 & 327509.2 \\
Nyeri & 9952442 & 274070 \\
New point (near the mountain) & 9982630.41 & 314670.071 \\
Batian & 9983767.1 & 311695.8 \\
\hline
\end{tabular}

The prediction of the glaciers was done using linear multiple regression equations in SPSS. This is because climatic predictions for rainfall and temperature had already been done using the EC- Earth model (for the period 2006 - 
2100) and the data for the two variables was acquired from Kenya Meteorological Department (KMD). Using these climate predictions, linear equations of the form $y=a_{1} x_{1}+a_{2} x_{2}+b_{o}$ were formed,

Where $\mathrm{y}=$ glacier coverage being predicted $a_{1} a_{2}$ and $b_{o}$ are constants obtained from SPSS.

$\mathrm{X} 1$ and $\mathrm{x} 2$ are the predicted Temperature and rainfall.

Figure 2 summarises the procedure that is explained here.

\section{Results and Discussion}

From the results of image classification, glacier recession has not been on a constant decline but there had been some years where there was a constant accumulation of ice. This trend can be shown by line graph (figure 6) and the classified images (figure $7-12$ ).

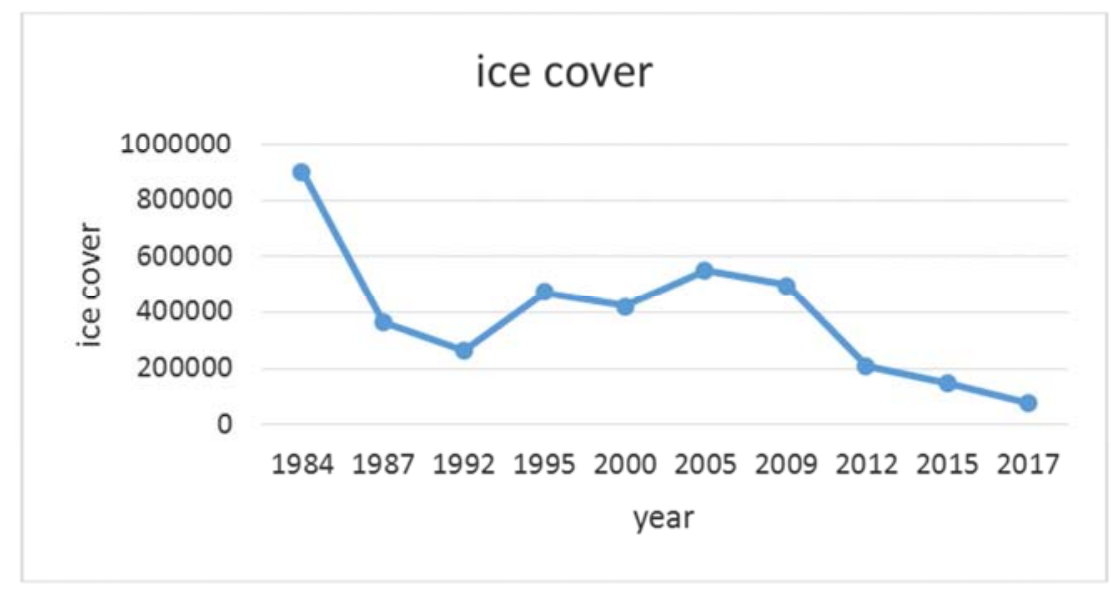

Figure 6. Mt Kenya Glacier Coverage Trend Curve.

\subsection{The Classified Images}

Some of the classified images that were used compute the areas of the glaciers for this study are shown by figures $7-12$.

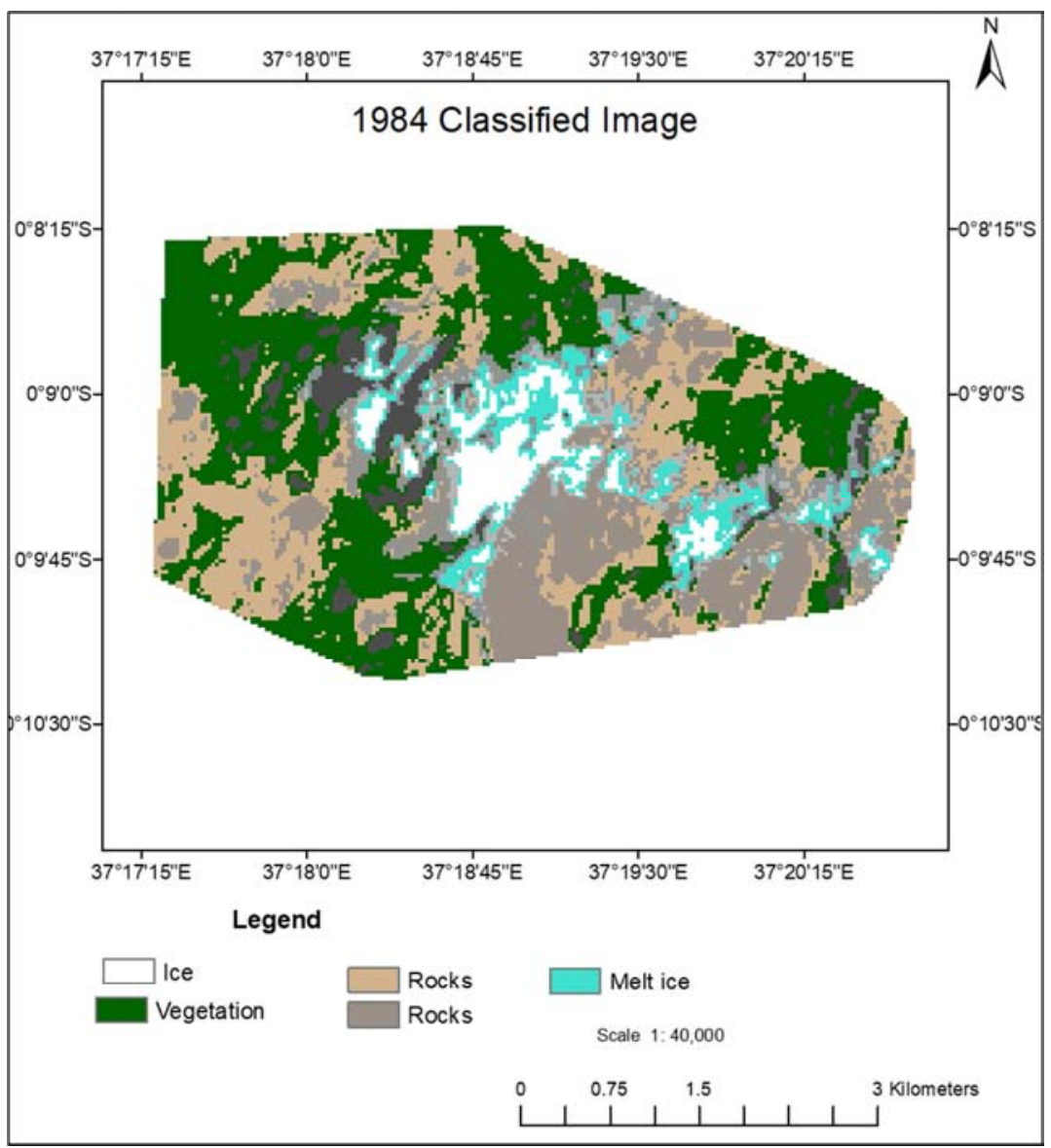

Figure 7. 1984 Glacier Coverage Classified Image. 


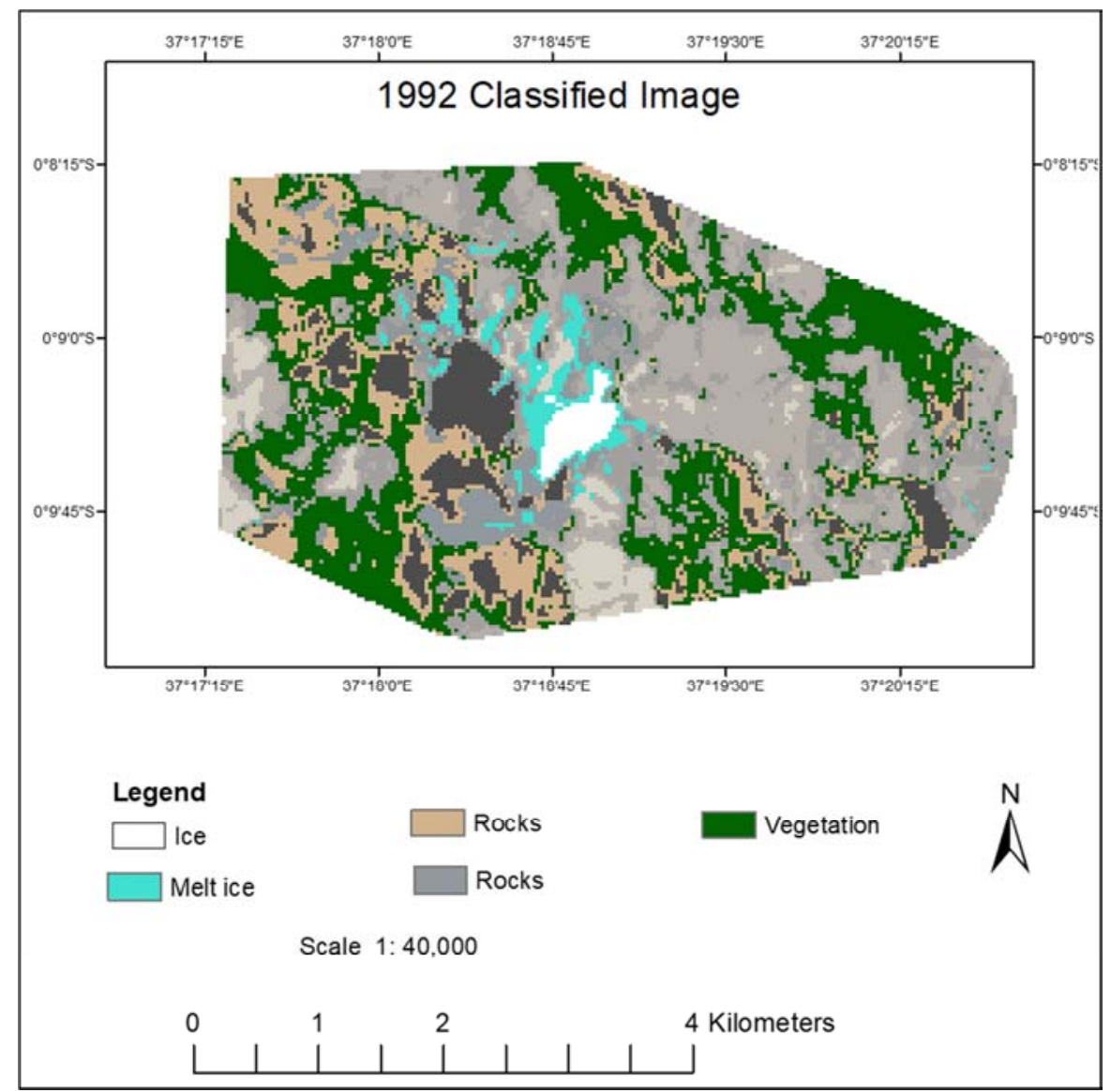

Figure 8. 1992 Glacier Coverage Classified Image.

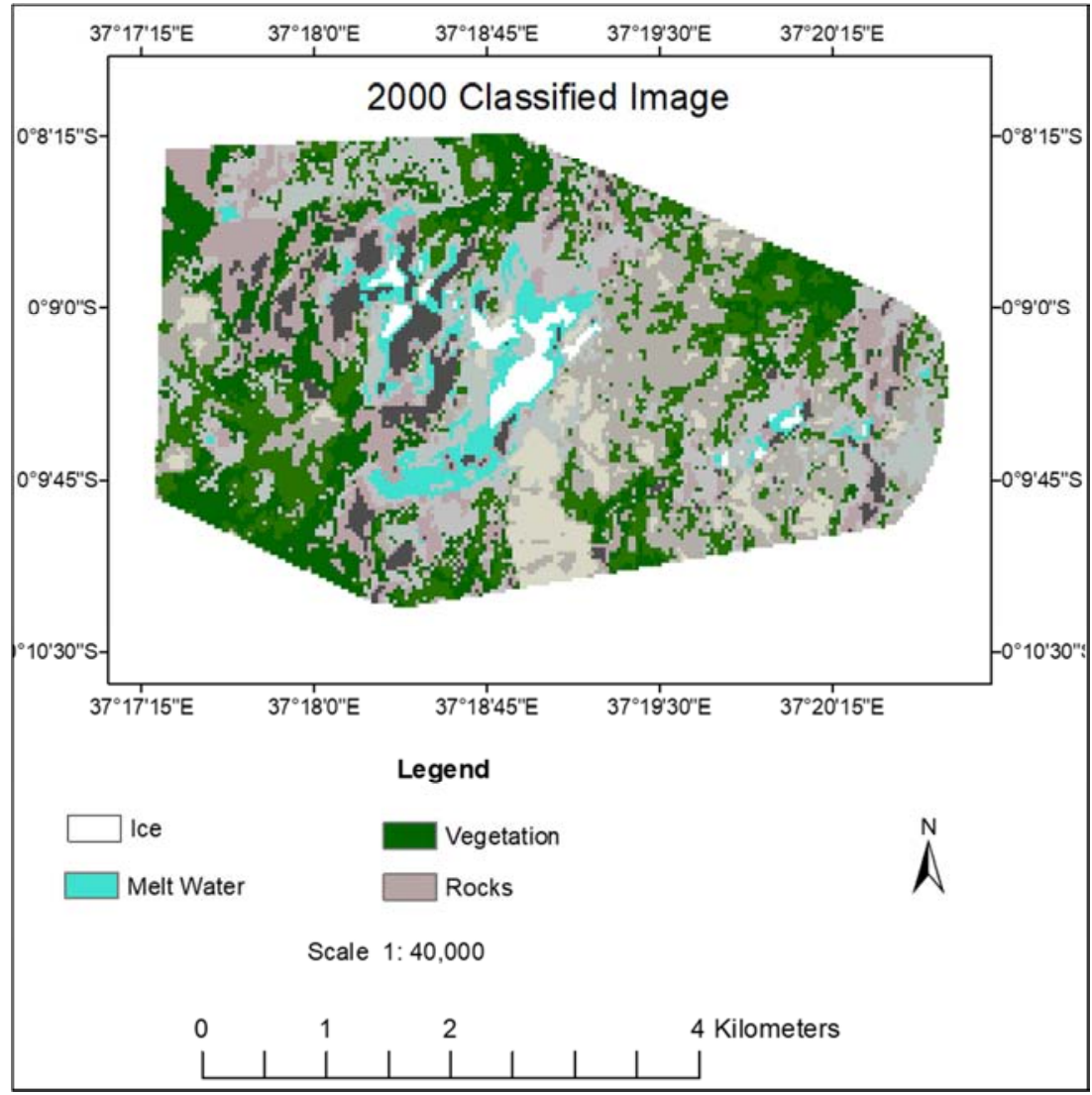

Figure 9. 2000 Glacier Coverage Classified Image. 


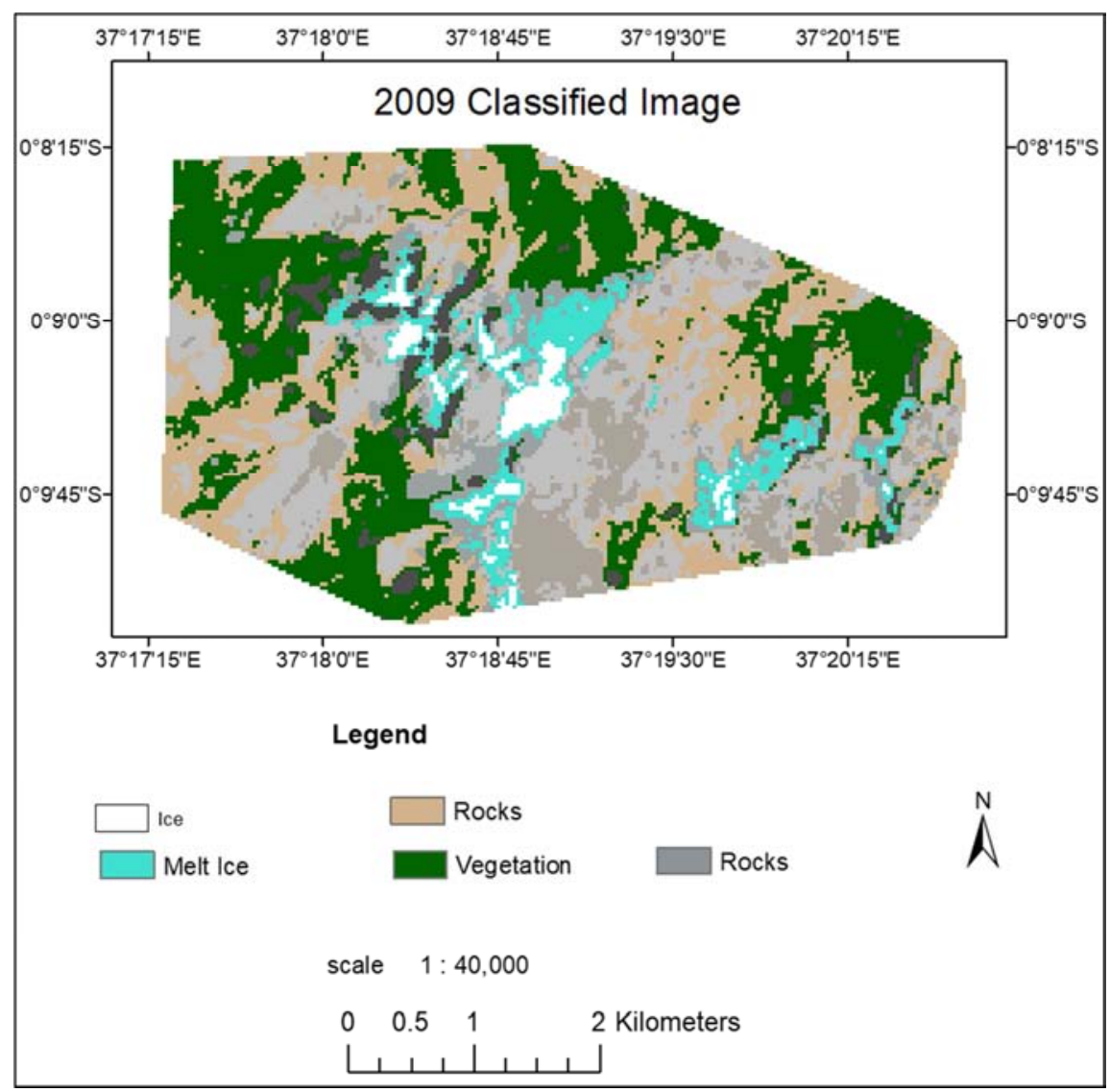

Figure 10. 2009 Glacier Coverage Classified Image.

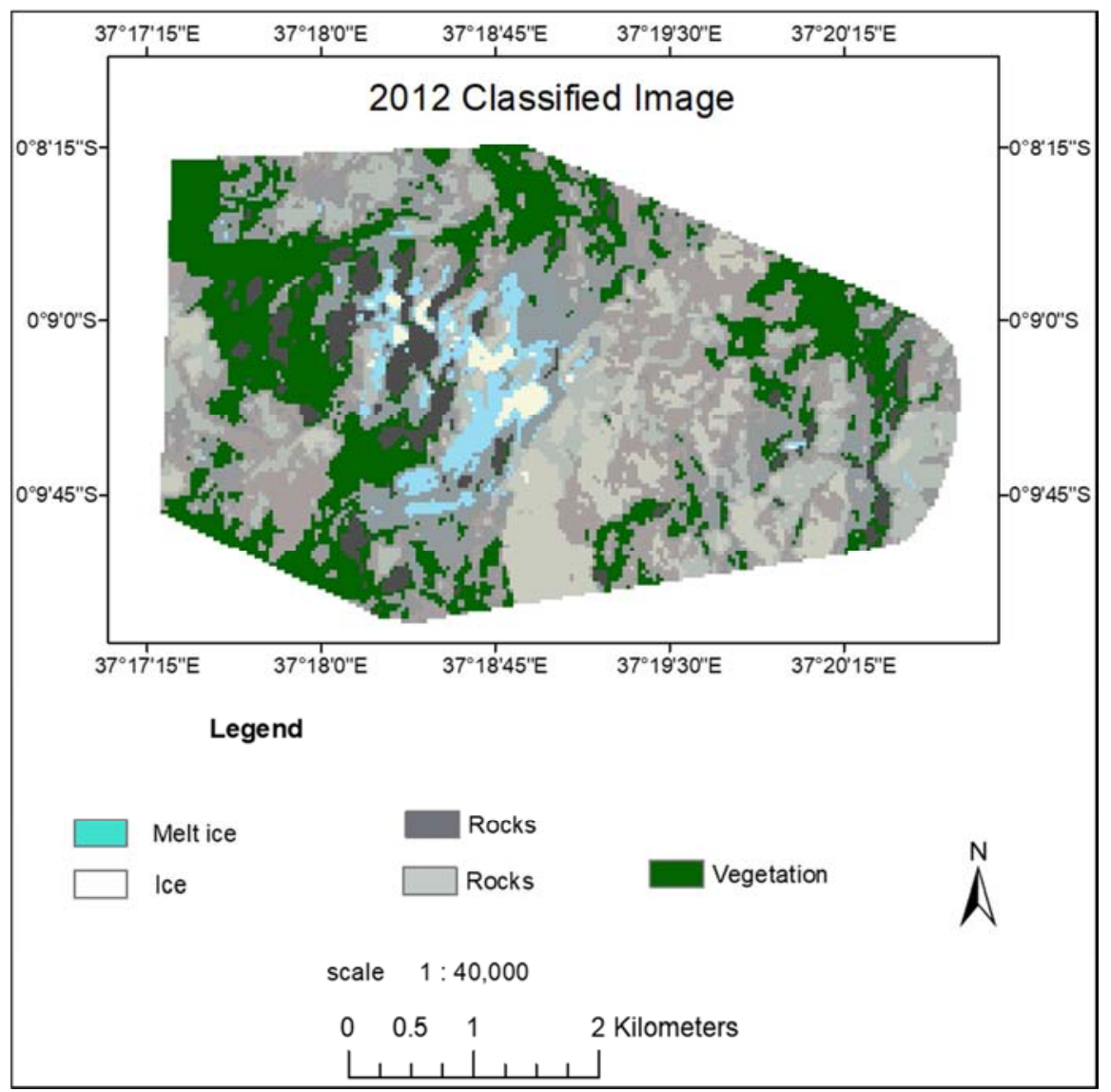

Figure 11. 2012 Glacier Coverage Classified Image. 


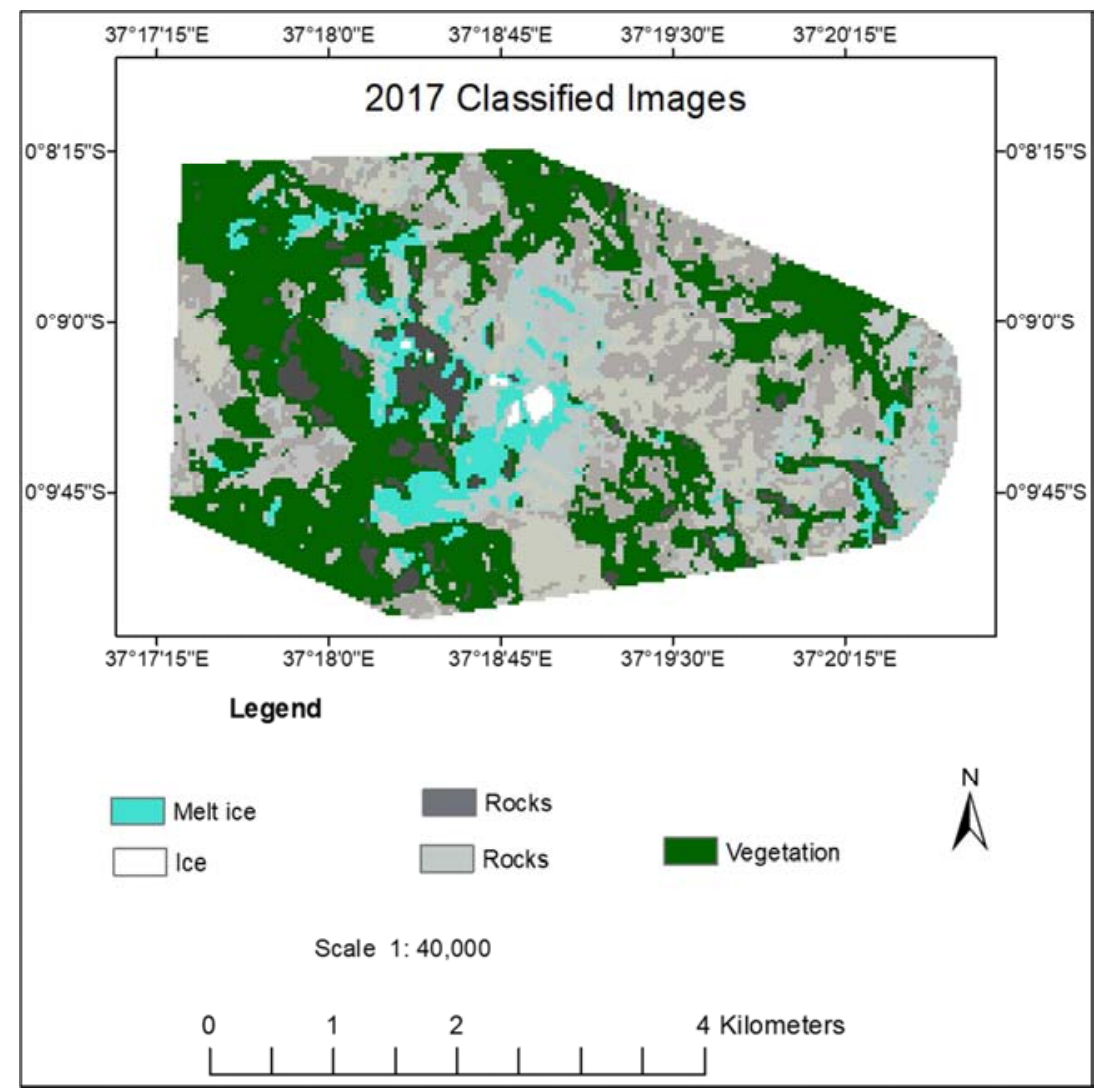

Figure 12. 2017 Glacier Coverage Classified Image.

The area coverage of Mt Kenya forest declined from 1984 to 1987 but between 1995 and 2012 the pace of decline reduced, this coverage is again on the decline as can be show by the trend curve below (figure 13).

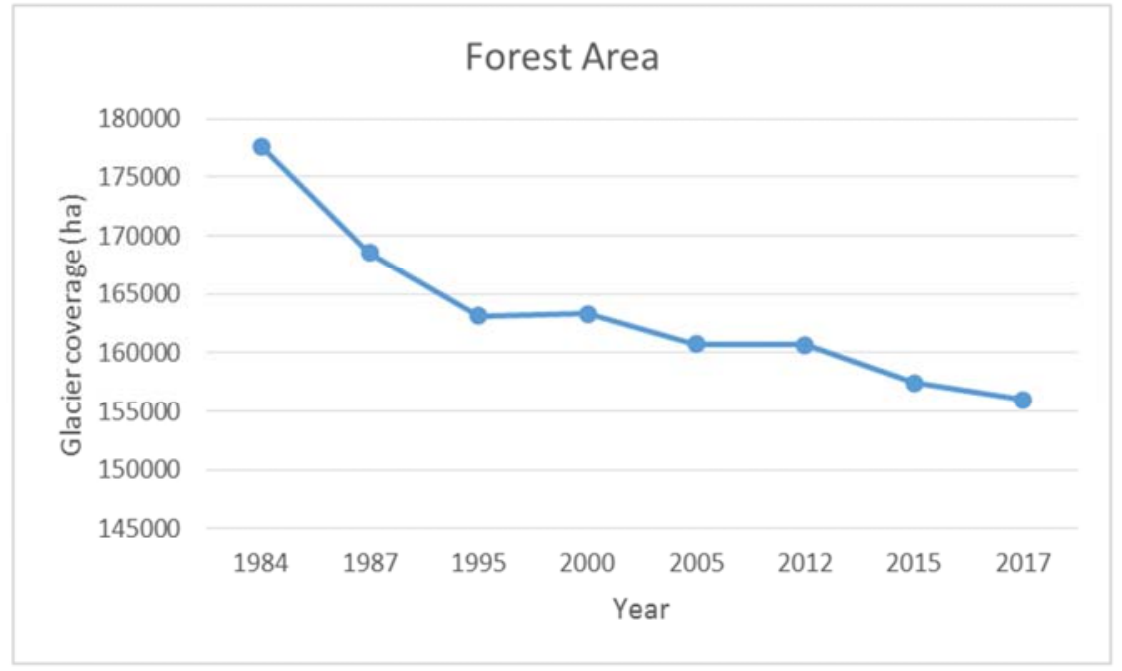

Figure 13. The Trend of Mt forest cover.

\subsection{The Relationship between Changes in Forest Cover and Climate Variables}

In order to determine the degree of relationships between the various variables and glacier recession, correlation coefficients $(R)$ and coefficients of determination $\left(R^{2}\right)$ were computed.

The changes in forest cover seemed to have had an effect on the climate variables. Increased forest cover had a negative correlation with temperature and humidity (it caused them to decrease). The same forest cover had a negative relationship with precipitation in that rainfall decreased despite increased forest cover. The wind speeds however increased with the increase in forest cover whereas solar insolation decreased with increase in forest cover. These correlations are shown on table 3 . 
Table 3. Climate variables VS Forest Cover Correlation.

\begin{tabular}{|c|c|c|c|}
\hline Forest cover vs Climate Variables & Correlation Coefficient (R) & Coefficient of Determination $\left(\mathbf{R}^{2}\right)$ & Magnitude of Correlation \\
\hline Forest cover vs temperature & -0.523 & $0.2737=28 \%$ & moderate \\
\hline Forest cover vs relative humidity & -0.45433 & $0.2064=21 \%$ & moderate \\
\hline Forest cover vs precipitation & -0.33414 & $0.1116=11 \%$ & weak \\
\hline Forest cover vs wind speed & 0.5931 & $0.3518=35 \%$ & moderate \\
\hline Forest cover vs solar insolation & -0.23994 & $0.0576=6 \%$ & weak \\
\hline
\end{tabular}

\subsection{The Relationship Between Forest Cover, Climate Variables and Glacier Coverage}

The relationship between relative humidity and glacier cover was negative and weak with $\mathrm{R}=-0.225$. The more the relative humidity was, the less glacier accumulation. Relative humidity was found responsible for $\mathrm{R}^{2}=0.051=5 \%$ of the changes in glacier coverage that occurred (figure 14).

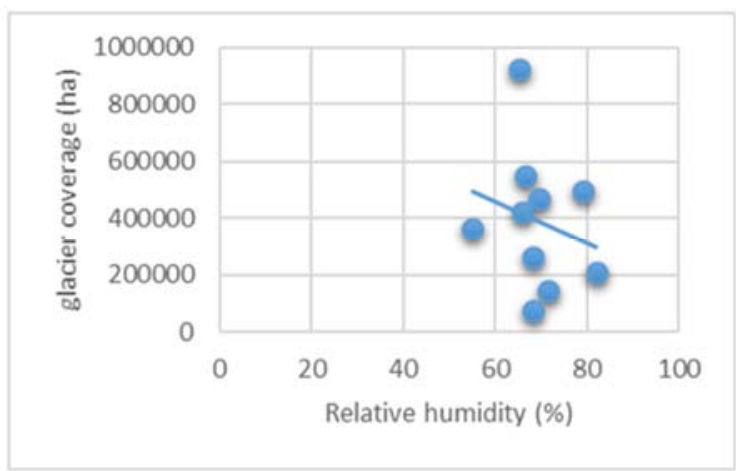

Figure 14. Glacier Coverage Vs Relative Humidity.

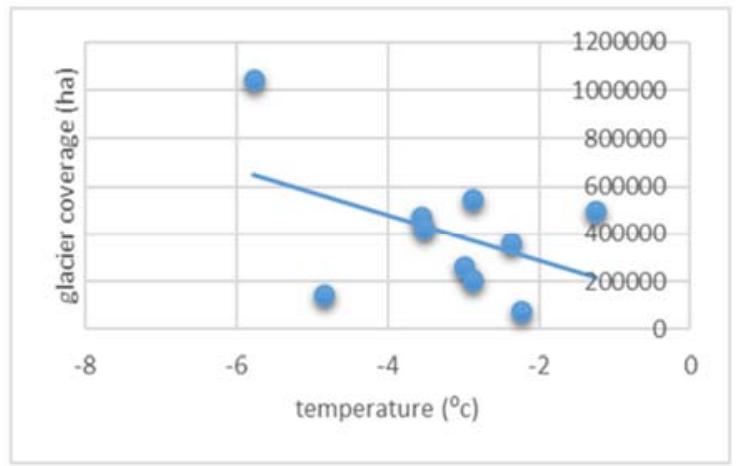

Figure 15. Glacier Coverage Vs Temperature.

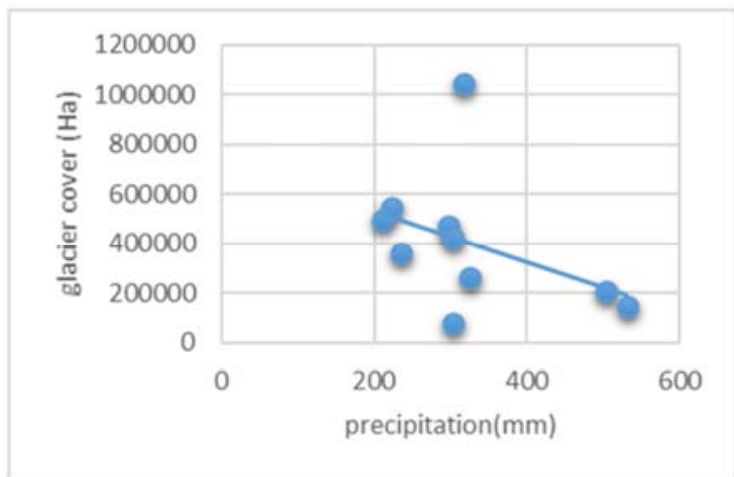

Figure 16. Glacier Coverage Vs Precipitation.

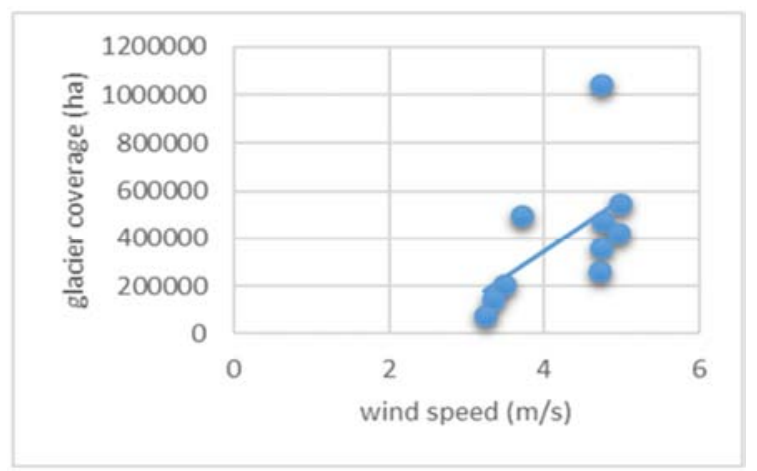

Figure 17. Glacier Coverage Vs Wind Speed.

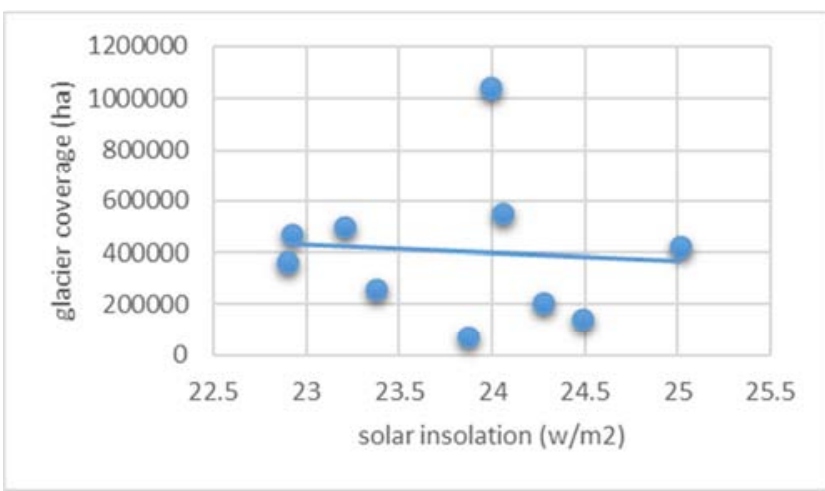

Figure 18. Glacier Coverage Vs Solar Insolation.

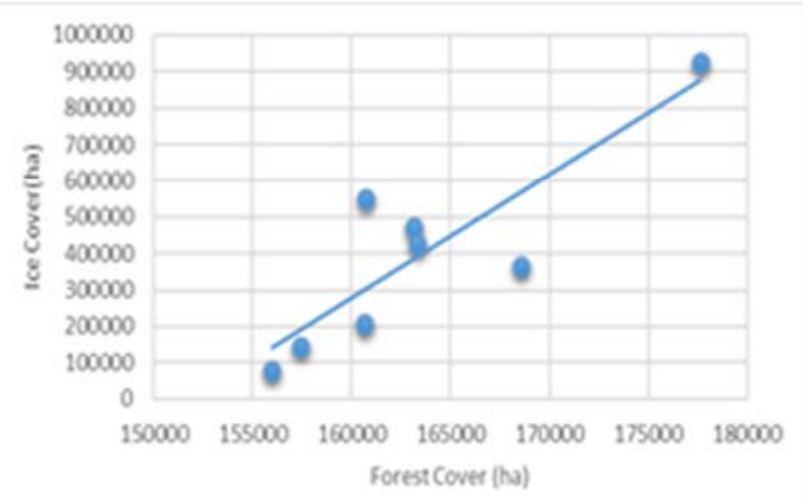

Figure 19. Glacier Coverage Vs Forest Cover.

The temperature and glaciers coverage had a negative and moderate correlation $\mathrm{R}=-0.40583$. It showed that the lower the temperature the more the glacier accumulation and vice versa. Temperature was responsible for $\mathrm{R}^{2}=0.1647=16 \%$ of the changes in glacier coverage (figure 15).

The precipitation and glacier coverage had a moderate and negative correlation of $\mathrm{R}=-0.45764$. This showed that the 
more the rainfall, the less the glacier coverage. Rainfall was found to have been responsible of $\mathrm{R}^{2}=0.2094=21 \%$ of the changes in glacier coverage recorded (figure 16).

Wind speed had a positive and moderate correlation with the glacier coverage. $\mathrm{R}=0.617739$. The more the wind speed the more the glacier accumulation was. This can be explained as; the accelerated wind speed lead to more cooling of air at the top of the mountain which resulted in more precipitation thus accelerate glacier accumulation. Wind speed caused $38 \%$ of glacier loss experienced during the period of study (figure 17).

For solar insolation, the assumption was that the more the sun exposure, the more the rate of glacier melt but there was barely any correlation with $\mathrm{R}=-0.09932$. This meant that the more the sun exposure the less the ice accumulation. Sun exposure was responsible of $1 \%$ of the glacier loss. $\mathrm{R}^{2}=0.009=1 \%$ (figure 18).
The relationship between forest and glaciers cover was positive and very strong $(\mathrm{R}=0.864576)$. Forest cover was responsible was responsible for $75 \%$ of the changes in glacier coverage that occurred during the period of study. $\mathrm{R}^{2}=0.7475$ $=75 \%$. This meant the more the forest cover, the more the glacier coverage (figure 19).

\subsection{Glacier Prediction}

To predict glacier coverage, temperature and rainfall were used as they were the only variables available. Bias correction had to be done because like in any other estimate, climate predictions are prone to bias.

In figures 20 and 21 the observed temperature and rainfall data for 1978-2005 are compared against model estimates for the same period for the one of the interpolating stations.

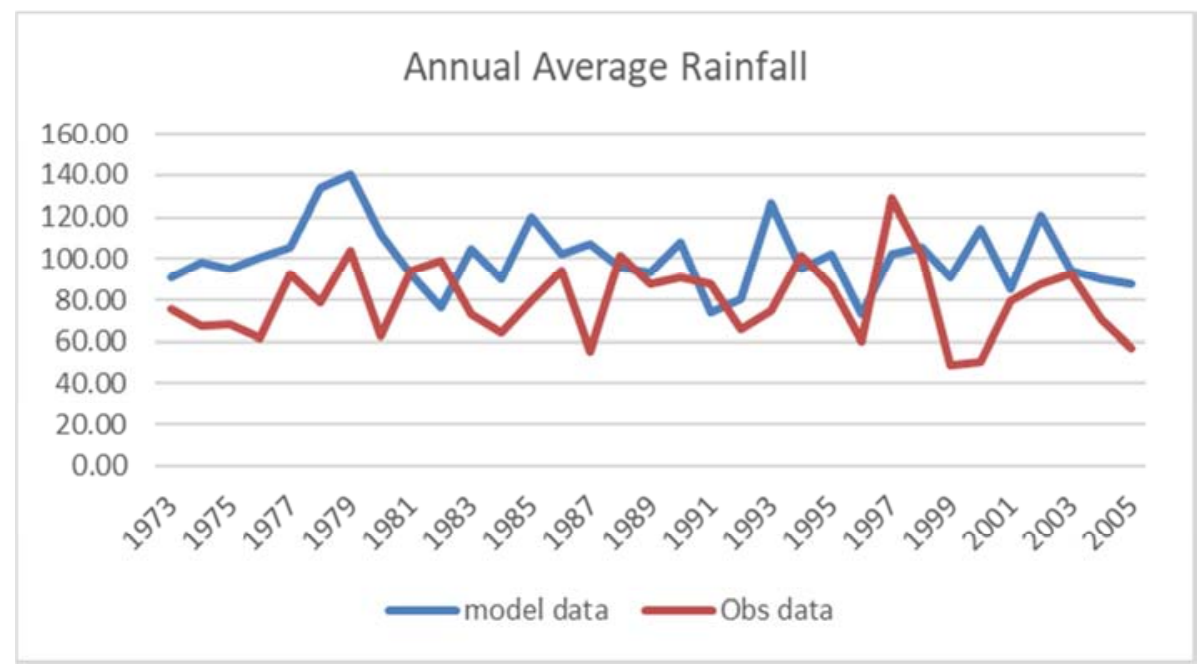

Figure 20. Comparison of Historical Observed rainfall and uncorrected estimates.

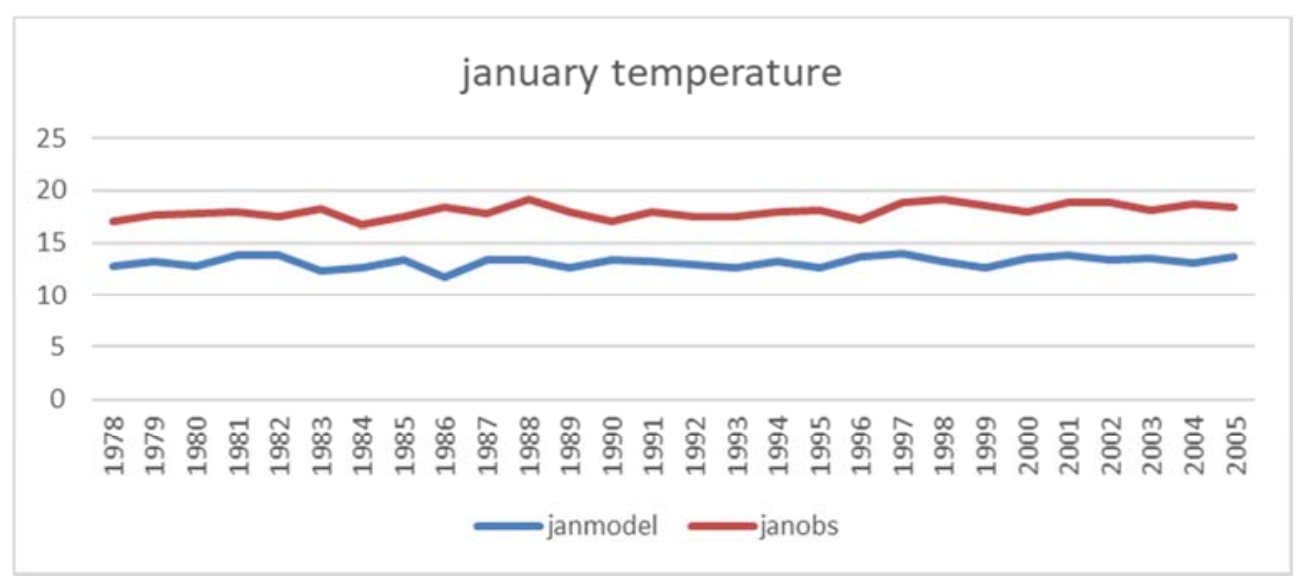

Figure 21. Comparison of Historical Observed Temperature and uncorrected estimates.

Where Janmodel is the model estimate and Janobs is the observed data for the same period. Obs data stands for observed rainfall for the same period. From figure 20, rainfall model data appears to be overestimated compared to temperature.

The climate estimates were extracted from the EC-Earth model for both temperature and rainfall, for RCP4.5 and RCP8.5. Computation of correction factors (i.e. the mean and standard deviation) of historical data were then done using the Simple Shift, Multiplicative and Delta methods explained in section 2.2. 


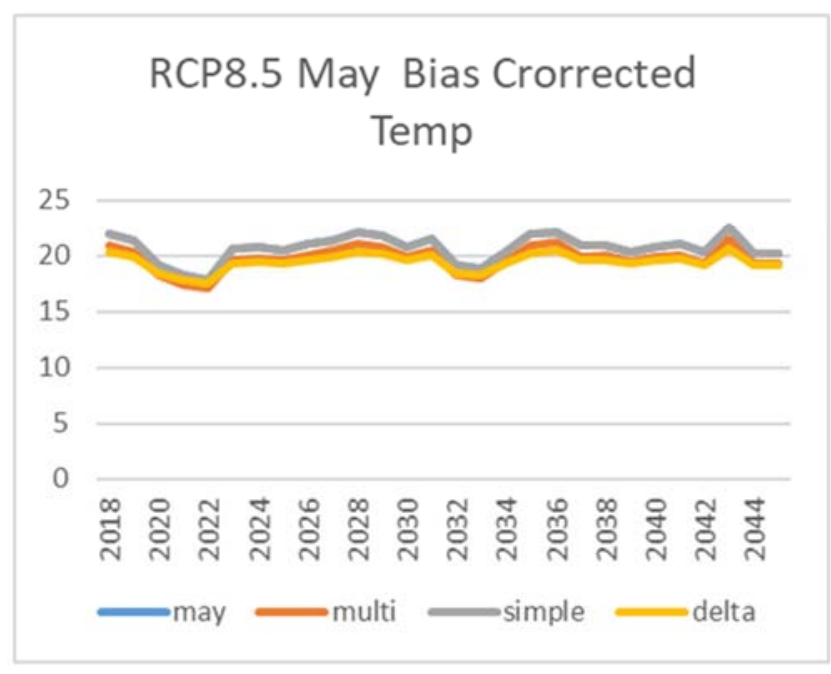

a

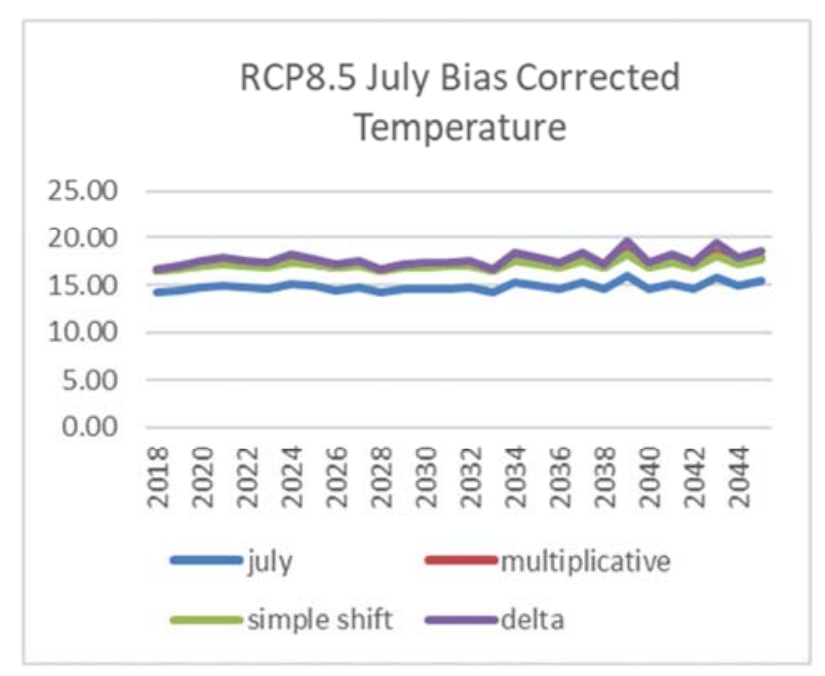

b

Figure 22. Comparison of Bias Correction methods.

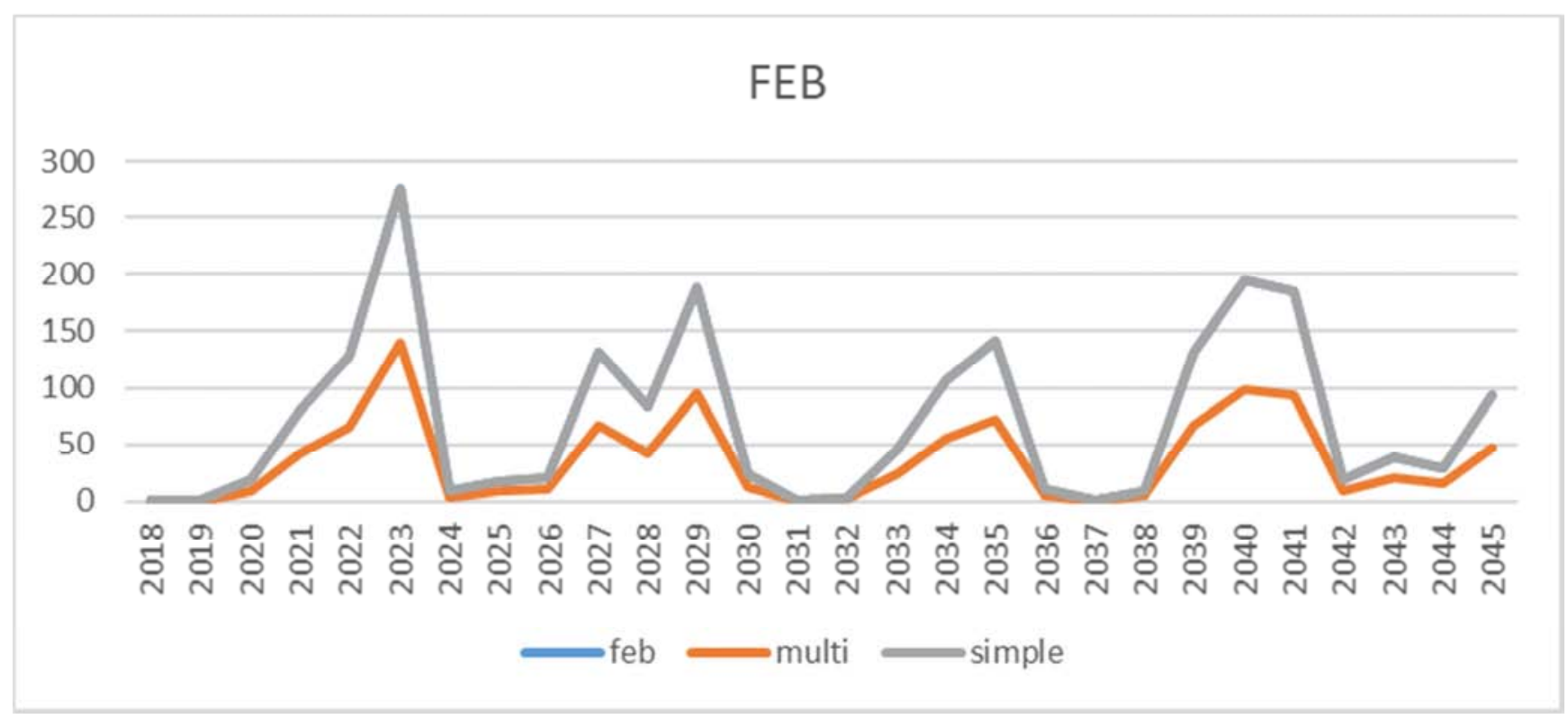

Figure 23. Comparison of Bias Correction Methods for February.

When the three methods of bias correction methods were compared, the Simple Shift method gave the best results as it sometimes had one on one fit with the model estimated data (figure 22). This was because of the conditional execution in the function which stated that, if the mean of model is greater than the mean of observation, then give output as the value of the model output (raw data) else, apply the simple shift equation. This was done to avoid getting negative values. Sometimes it fitted in between the Delta and the multiplicative method as the mean of the two.

The Delta method had in some instances negative values and at other instances very abnormal protrusions as can be shown on the figures 23. So was the Multiplicative method.

Once corrected for bias the Temperature and rainfall model output data was then used to interpolate the temperature and rainfall for the top of the mountain. A boundary was digitized around the four points listed in table 2, then interpolation done using the IDW technique. 


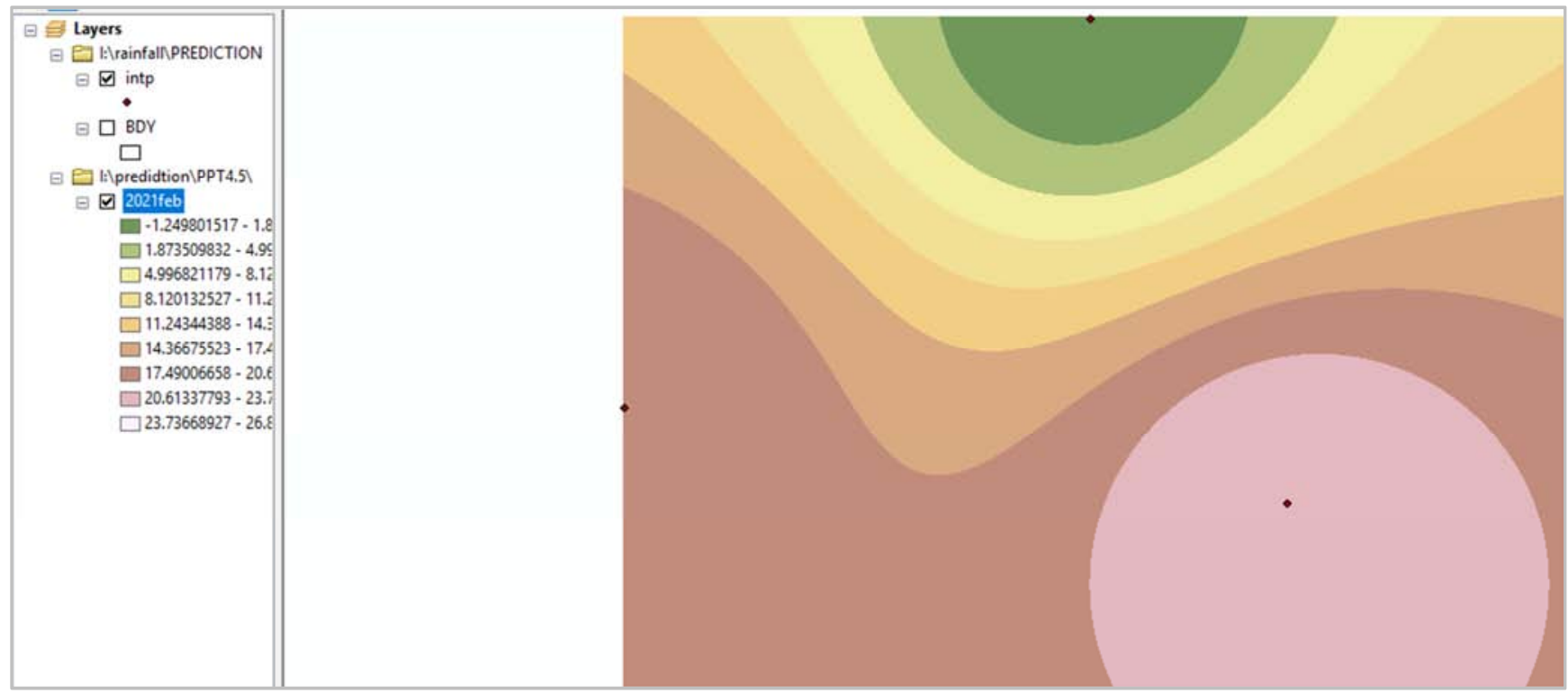

Figure 24. Results of Temperature Interpolation in ARCGIS using IDW Technique.

From the resultant raster like the one shown in figure 24, extraction of temperature and rainfall for a point on top of the mountain whose coordinates were (9983767.1 MN, 311695.8ME) was done. The interpolation results for both variables based on RCP8.5 and RCP 4.5 bias corrected temperature and rainfall for the top of the mountain are shown in the figure 25 and 26 below.

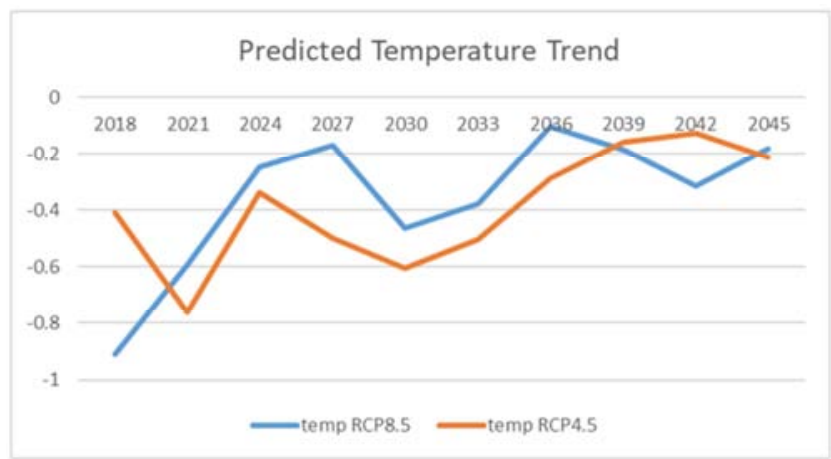

Figure 25. Predicted Temperature trend based on both RCP 8.5 and RCP 4.5.

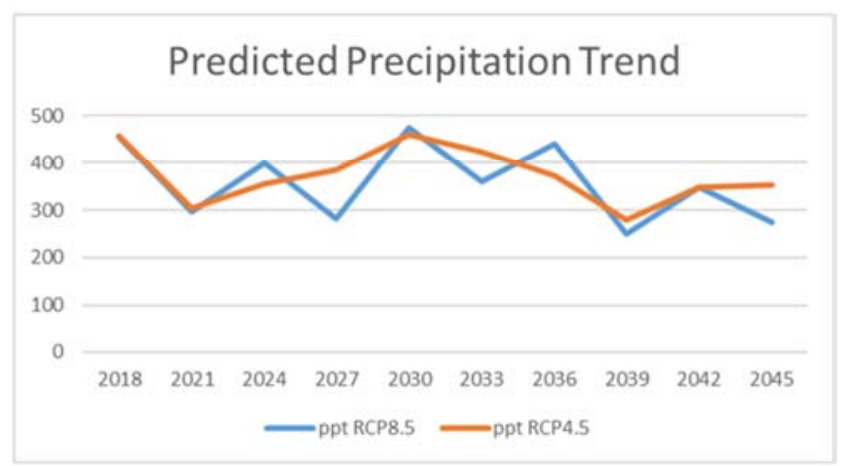

Figure 26. Predicted rainfall trend based on both $R C P 8.5$ and $R C P 4.5$.
RCP8.5 is a scenario that is characterized by increase in greenhouse emission over the years. From figure 25 it can be seen that compared to RCP 4.5 the temperature based on RCP8.5 will be higher over the span of the period of study. RCP4.5 is a stabilization scenario in which total radiative forcing is stabilized shortly after 2100 , without overshoot by the application of a range of technologies and strategies for reducing greenhouse gas emissions. Therefore, RCP 4.5 is a more reliable scenario compared to 8.5.

Given that RCP4.5 is a stabilization scenario, if the climate stabilises where it is now, the amount of precipitation being received on Mt Kenya will decrease and reach its lowest in 2021 after which it will gradually increase and dip again in 2030. Based on RCP8.5 the same will have several peaks and lows as can be shown by figure 26 .

\subsection{Predicted Glacier Coverage}

The predicted temperature and precipitation above were then input in SPSS (a statistical analysis Software) in order to form an equation of the form $y=a_{1} x_{1}+a_{2} x_{2}+b_{0}$. For the RCP8.5, $x_{1}, x_{2}$ and $b_{0}$ were _0.455, 0.381 and -157.083. For RCP $4.5 \mathrm{x}_{1}, \mathrm{x}_{2}$ and $\mathrm{b}_{\mathrm{o}}$ were $-0.175,0.579$ and $-227.409 . \mathrm{a}_{1}$ and $\mathrm{a}_{2}$ were the predicted temperature and precipitation respectively.

The predicted glacier coverage is as shown in the figure 27 . From the figure it can be seen that just like 1984 to 2017 where the glacier coverage did not have a steady decline but it appeared to peak and decline alternately, so did the predicted glacier coverage. This suggested that although the glacier coverage is going to thin down, it would not do so in a straight line of decline. 


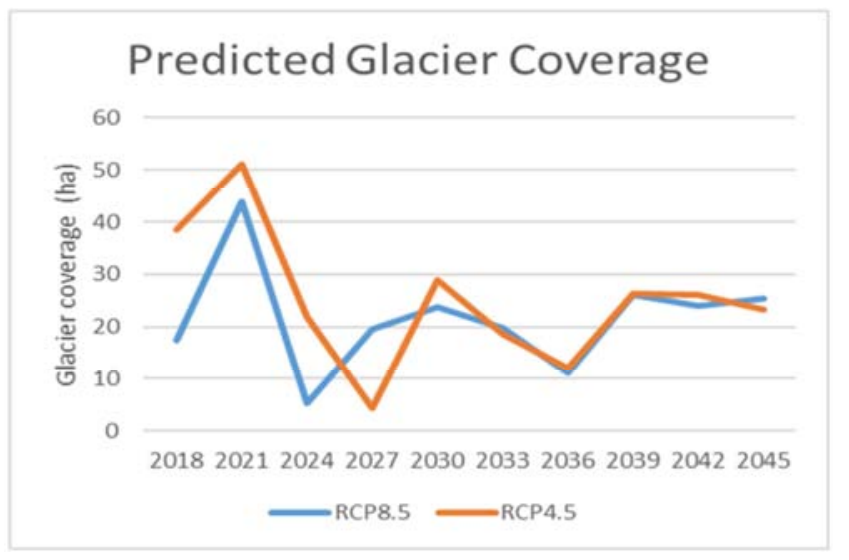

Figure 27. Predicted Glacier Coverage based on RCP4.5 and RCP8.5.

\section{Conclusion and Recommendation}

\subsection{Conclusion}

As can be shown on figure 6, the glacier cover on Mt Kenya has not been steadily decreasing but there has been years where there has been an increase.

From the results of correlation obtained, it came out forest had the largest correlation with glacier coverage. Suggesting that if forest can be increased, glacier coverage would increase. The correlation between glacier coverage and forest cover was very strong $(\mathrm{R}=0.864576)$ therefore forest cover was responsible was responsible for $75 \%$ of the changes in glacier coverage that occurred during the period of study.

Temperature had a negative and moderate correlation $\mathrm{R}=$ 0.40583 . This meant that lower temperature would lead to more glacier accumulation and vice versa. Temperature was responsible for $16 \%$ of the changes in glacier coverage. Overall the average temperature also warmed by $-0.931{ }^{\circ} \mathrm{C}$ between 1984 and 2015. These changes can be attributed to the accelerated rate of deforestation which was witnessed in Mt Kenya.

Precipitation had a negative correlation with glacier coverage of $\mathrm{R}=-0.45764$. This showed that despite there having been more amount of rainfall during the period of study, the glacier accumulation was less. Rainfall was found to have been responsible for $21 \%$ of the changes in glacier coverage recorded

As mentioned earlier precipitation may increase in amounts but if temperatures are high, they cause the precipitation to fall in from of rainfall instead of snow that replenish the glaciers hence the reason why glacier coverage still continues to decline.

Solar Insolation and Relative Humidity barely had any relationship with the glacier coverage having a correlation coefficient of $\mathrm{R}=-0.09932$ and $\mathrm{R}^{2}=0.0099$ and $\mathrm{R}=-0.225$ and $\mathrm{R}^{2}=0.0506$ respectively. The fact that Relative Humidity was found to have barely any relationship with the changes that were experienced in glacier coverage contradicted with the previous findings where they found relative humidity to have been the major driver of Mt Kenya Glacier recession [23].
From the results of climate prediction, the amount of rainfall being recorded on the Mountain will decline overall based on both scenarios as can be shown in figure 26. At the same time, the temperature for the same period will generally increase whether the current climate situation stabilizes or accelerates.

As a result of that, when temperature and precipitation were used to do prediction of glacier coverage, the results showed that the future glacier coverage is going to decline but not as steadily as it is doing at present. This is because from the analysis of the correlations between glacier coverage, climate variables and Forest cover, temperature and precipitation did not come out as the major drivers of glacier recession. This meant that if the predicted data for all the other variables would have been available, the predicted glacier coverage curve would have declined more steeply. Nevertheless, based on the trend of prediction using the two variables there is going to be no glacier remaining on the mountain by the year 2100 as was found by a previous research on the same [4].

Given that Mt Kenya glaciers will continue thinning based on both RCP4.5 and 8.5 scenarios predictions, the current trend of drying rivers especially the ones that have their catchment in Mt Kenya forest is going to continue. So is the water shortage that is being experienced currently due to falling water levels in dams, power rationing and failing crop yield due to lack of rainfall as a result deforestation. Mitigation measures therefore need to be taken to reverse the trends of deforestation and climate change although locally there is only so much that we do about climate change since global warming which causes climate change is a global problem.

\subsection{Recommendation}

Since from analysis of the results of correlations it emerged that deforestation, higher temperatures which cause precipitation to fall as rain instead of snow are some of the major drivers of glacier recession, some of the mitigation measures that can be taken to address this issues are:

Climate predictions are based on greenhouse gases emission scenarios. To reduce emission of these gases we should increase the use of renewable energy sources (e.g. wind and power), and halt investment in the new coal mining being explored.

The government should also ensure the gains made so far of ensuring that Kenya goes back to where it was in 1963 in terms of $10 \%$ forest cover by the year 2030 are not lost but accelerated given that by the end of 2012 progress had been made by achieving a $6 \%$ cover up from $2 \%$ (in the entire Kenya).

Forests act as carbon deposits and the more the forest cover the cooler our country will be, the more the glacier area coverage will improve. This also translates to more rain, a more food productive country and healthier population.

Control population growth because the more the population grows, the more the encroachment to forested areas in search of more agricultural land for food production and fuel.

The cost of high resolution data was a limiting factor for 
this research, it would be recommended that for the purpose of comparison of accuracies, the future researches on the same area be done with such data.

\section{Acknowledgements}

I would also like to thank the Kenya Meteorological Department and the Regional Centre for Mapping of Resources for Development for providing the major datasets that were used in this research. I also wish to express my deepest gratitude to my supervisors David Kuria, Charles Mundia and Godfrey Makokha who continuously directed and shared ideas with me on how to go about the difficulties encountered during the course of this research.

\section{Conflicts of Interest}

The authors declare no conflict of interest.

The funding sponsors had no role in the design of the study; in the collection, analyses, or interpretation of data; in the writing of the manuscript, and in the decision to publish.

\section{References}

[1] Singh, P. and V. P. Singh (2001). Snow and glacier hydrology. In Water Science and Technology Library, Vol. 37. Kluwer Academic Publishers.

[2] Richard S. Williams, J. (1977). Glaciers:Clue for Future Climate. USGS: Science for Changing the World, 2-3.

[3] Hastenrath, Stefan. (2008). Recession of equatorial glaciers: photo documentation. Sundog publishing, Madison, WI.

[4] Ouma, Y. O., \& Tateishi, R. (2005). Optical satellite - sensor based monitoring of glacial coverage fluctuations on Mount Kenya, 1987-2000. International Journal of Environmental Studies, 62(6), 663-675.

[5] Young, J. and Hastenrath, S. (1991). "Glaciers of the Middle East and Africa - Glaciers of Africa." In Satellite Image Atlas of Glaciers of the World, edited by R. S. Jr. Williams and Jane G. Ferrigno. U.S. Geological Survery Professional Paper 1386-G-3, 1991.

[6] Thompson, L. G., H. H. Brechera, E. Mosley-Thompson, D. R. Hardy, and B. G. Mark. (2009). "Glacier loss on Kilimanjaro continues unabated." (Proceedings of the National Academy of Sciences (PNAS)) 106, no. 47 (2009): 19770-5.

[7] Campbell, R. (2008). Mount Kilimanjaro, Tanzania: 1976, 2000. U.S. Geological Survey. 2008. http://earthshots.usgs.gov (accessed on $6^{\text {th }}$ April, 2017).

[8] Cullen, N., T. Mölg, G. Kaser, K. Hussein, K. Steffen, Hardy, D (2006). Kilimanjaro Glaciers: Recent areal extent from satellite data and new interpretation of observed 20th century retreat rates, Geophysical Research Letters, 33, L16502.

[9] UNEP. (2005a). One Planet, Many People: Atlas of Environmental Change. Nairobi: United Nations Environment Programme.

[10] Jr, J. G. F., Nair, U. S., Christopher, S. A., \& Mölg, T. (2011). Land use change impacts on regional climate over Kilimanjaro, 116(October 2010), 1-24. https://doi.org/10.1029/2010JD014712

[11] Duane, W. J., \& Hardy, D. R. (2014). Measuring and modeling the retreat of the summit ice fields on Kilimanjaro, East Africa, 46(4), 905-917.

[12] UNEP. (2005). One Planet, Many People: Atlas of Environmental Change. Nairobi: United Nations Environment Programme.

[13] Hastenrath. S. (2010). Climatic forcing of glacier thinning on the mountains of East Africa. International Journal of Climatology 30: 146-152.

[14] Prinz, R., Nicholson, L., \& Kaser, G. (2012). Variations of the Lewis Glacier, Mount Kenya, 2004-2012. Erdkunde, 66(3), 255-262.

[15] Prinz, R.; Fischer, A.; Nicholson, L. and Kaser, G. (2011): Seventy-six years of mean mass balance rates derived from recent and re-evaluated ice volume measurements on tropical Lewis Glacier, Mount Kenya. In: Geophysical Research Letters 38 (20), L20502.

[16] Kenya Wildlife Service, (1999). Aerial Survey of the Destruction of Mt Kenya and Ngare Ndare forest reserves february - june 1999.

[17] Bhatt, N. 1991. The geology of Mount Kenya. In: Allen I, editor. Guide to Mount Kenya and Kilimanjaro. Nairobi, Kenya: The Mountain Club of Kenya, pp. 54-66.

[18] Gregory, J. W. (1894). "Contributions to the Geology of British East Africa.-Part I. The Glacial Geology of Mount Kenya". Quarterly Journal of the Geological Society 50: 515-530.

[19] Rough Guide (2006). Rough Guide Map Kenya (Map). 1:900,000. Rough Guide Map. Cartography by World Mapping Project ( $9^{\text {th }}$ Edition).

[20] Kenya Forest Services, M. (2010). Mt Kenya Reserve Management plan 2010-2020.

[21] Nicholson, L. I., \& Prinz, R. (2013). The Cryosphere Micrometeorological conditions and surface mass and energy fluxes on Lewis Glacier, Mt Kenya, in relation to other tropical glaciers, 1205-1225. https://doi.org/10.5194/tc-7-1205-2013

[22] Berg, P., Feldmann, H., \& Panitz, H. (2012). Bias correction of high resolution regional climate model data. Journal of Hydrology, 448-449, 80-92.

[23] Prinz, R., Nicholson, L. I., Mölg, T., Gurgiser, W., Kaser, G., \& Prinz, C. R. (2016). Climatic controls and climate proxy potential of Lewis Glacier, Mt. Kenya, 133-148. https://doi.org/10.5194/tc-10-133-2016. 